\title{
CONTEXTO DE PERCEPCIÓN GENERADO EN TWITTER \\ PARA LOS DEBATES ELECTORALES ESPAÑOLES DE \\ DICIEMBRE DE 2015 Y JUNIO DE 2016: TRATAMIENTO \\ DE LOS FACTORES DE CREDIBILIDAD POR LOS \\ CANDIDATOS
}

https://doi.org/o0.000/CoO-202O-O1

\author{
Dr. Alfredo Arceo Vacas \\ Universidad Complutense, Madrid, España \\ aarceo@ucm.es \\ ORCID iD: https://orcid.org/0000-0002-5981-4397 \\ Dr. Rafael Barberá González \\ Universidad Complutense, Madrid, España \\ rbarbera@ccinf.ucm.es \\ ORCID iD: https://orcid.org/00oo-0001-7471-3992 \\ Dr. Sergio Álvarez Sánchez \\ Universidad Complutense, Madrid, España \\ sergioalvarezsanchez@ucm.es \\ ORCID iD: https://orcid.org/o0oo-0002-7494-8991
}

Recibido el 16 de octubre de 2019

Aceptado el 11 de mayo de 2020

\section{Resumen}

Como red social, Twitter ha generado una nueva forma de consumir debates electorales; mediante el fenómeno de la doble pantalla, los espectadores sintonizan el debate mientras atienden a los comentarios. Así, el contexto creado en Twitter impacta en la credibilidad de los candidatos. Credibilidad, atractivo y poder constituyen los tres factores de la imagen en comunicación política; la credibilidad se compone a su vez de tres subfactores: conocimiento 
experto, la fiabilidad ética y eficacia social. La presente investigación describe los contextos de credibilidad perseguidos en Twitter por los cuatro principales candidatos a la presidencia del Gobierno español para las elecciones generales de 2015 y 2016. También se analiza la evolución de los factores de credibilidad, tomando como referencias el debate entre Mariano Rajoy y Pedro Sánchez de diciembre de 2015; y el mantenido entre los cuatro aspirantes, en junio de 2016. Asimismo, se exploran los marcos de percepción del público joven sobre la credibilidad de los candidatos en debates. Mediante el estudio de encuestas, la realización de grupos de discusión y el análisis de contenido de los perfiles en Twitter de los candidatos, se ha definido el contexto de percepción. Además, los análisis de contenido han recogido las variables empleadas por los candidatos para resultar creíbles. Mientras todos intentaban transmitir eficacia social, dicho subfactor fue el menos reconocido por los públicos. La celebración de los debates apenas cambió las prácticas en redes, pero la naturalidad de Mariano Rajoy en ellos resultó más creíble que los esfuerzos artificiales de sus adversarios.

Palabras clave: comunicación política, debates electorales, redes sociales, credibilidad, Twitter, análisis de contenido. 


\title{
THE CONTEXT OF PERCEPTION GENERATED ON TWITTER FOR THE SPANISH ELECTORAL DEBATES OF DECEMBER 2015 AND JUNE 2016: TREATMENT OF THE CREDIBILITY FACTORS BY THE CANDIDATES
}

\begin{abstract}
As a social network, Twitter has generated a new way of consuming electoral debates; through the double screen phenomenon, spectators watch the debate while they pay attention to the comments. Consequently, the credibility attributed to candidates gets influenced by the context created on Twitter during the campaign. Credibility, appeal and power constitute the three image factors in political communication; equally, credibility is made of three subfactors: Expert knowledge, ethical trustworthiness and social efficacy. This research describes the credibility contexts which the four main candidates to the presidency of the Spanish Government tried to implement in Twitter, when heading to the 2015 and 2016 general elections. The evolution of the credibility factors is also analyzed, taking two events as references: The debate between Mariano Rajoy and Pedro Sánchez in December 2015; and the June 2016 debate among all four contenders. Equally, the perception frames for the credibility of the candidates among the young public was also analyzed. The context of perception has been defined after studying the polls, organizing focus groups and conducting content analyses of the Twitter profiles of the candidates. In addition, those content analyses registered the variables that candidates applied in order to look credible. While everybody tried to transmit social efficacy, this subfactor received almost no recognition from audiences. The debates did not change the practices on social media, but the spontaneity of Mariano Rajoy was revealed as more credible than the artificial efforts of his adversaries.
\end{abstract}

Keywords: political communication, electoral debates, social media, credibility, Twitter, content analysis. 


\section{Introducción}

La presente investigación analiza el papel de la red social Twitter en la generación de contextos de percepción sobre la credibilidad de los candidatos a la presidencia del Gobierno español, durante las campañas electorales correspondientes a los comicios del 20 de diciembre de 2015 y el 26 de junio de 2016. El trabajo llevado a cabo se centra especialmente en la posible contribución de los mensajes en Twitter a que la audiencia de un debate electoral perciba dicho atributo de credibilidad en un candidato.

Para las elecciones de diciembre de 2015 se toma como referencia el debate cara a cara entre el presidente del Gobierno en funciones y candidato del Partido Popular (PP), Mariano Rajoy, y el candidato del Partido Socialista Obrero Español (PSOE), Pedro Sánchez, celebrado el 13 de diciembre; en el caso de las elecciones de junio de 2016, se analiza el contexto de percepción que rodeó al debate entre los cuatro principales candidatos a la presidencia, el cual tuvo lugar el 14 de junio. La proximidad de estas dos citas electorales se debió a la falta de acuerdo para formar gobierno entre las fuerzas políticas tradicionales (el conservador PP y el socialdemócrata PSOE) y los por entonces partidos emergentes (la izquierda alternativa de Podemos -con Pablo Iglesias como candidato- y la formación liberal Ciudadanos -encabezada por Albert Rivera-).

A lo largo de las últimas décadas, durante las campañas electorales, los debates se han convertido en una parte sustancial de la comunicación política, la cual:

[...] estudia los actores, roles, comportamientos, estrategias discursivas y patrones de argumentación implicados en la producción del discurso político -mensajes, periodistas, políticos, asesores, consultores, auditorio-, las instituciones desde las que actúan -partidos, gobiernos, parlamentos, medios de comunicación, consultorías-, los nuevos soportes tecnológicos que vehiculan los mensajes Internet-, y las relaciones que mantienen [...]. (Del Rey Morató, 2011: 107)

Sin embargo, en tanto que los candidatos tienen que establecer y mantener relaciones beneficiosas con sus votantes potenciales, un debate electoral también se enmarca dentro del concepto de relaciones públicas políticas, tal y como lo entienden Strömbäck y Kiousis (2011); y, si existe un espacio en el que los políticos pueden cultivar de forma rápida y directa tal bidireccionalidad, éste es la red social de microblogging Twitter, que ofrece nuevas posibilidades de comunicación transversal y difusión de los mensajes. 
Tres son los objetivos con los que se ha diseñado esta investigación: En primer lugar, describir el contexto de credibilidad percibida que los candidatos trataron de generar a través de sus cuentas en Twitter, para comprender el papel que jugaron sus perfiles en esta red social durante las campañas para las elecciones generales de 2015 y 2016 en España; es decir, hallar la evolución de las temáticas y de las estrategias por las que intentaron revestirse de credibilidad, y cómo éstas pudieron evolucionar tras la celebración de un gran debate electoral. En segundo lugar, explorar qué marcos o esquemas mentales de percepción entran en juego entre los públicos, a la hora de evaluar la credibilidad de un candidato durante un debate electoral. Por último, se pretenden extraer las principales variables de las que los cuatro principales candidatos se sirvieron para tratar de reforzar su credibilidad.

Para ofrecer un análisis riguroso de todas estas cuestiones, el presente trabajo comienza por exponer el estado de la cuestión sobre el uso de Twitter para la comunicación política y las campañas electorales, y sobre el potencial de los debates en este nuevo tablero mediático. A continuación, se vinculan los debates electorales a los estudios sobre credibilidad y teoría del enmarcado en el ámbito de la Comunicación Social.

Los resultados del trabajo de campo recogen un análisis cuantitativo exhaustivo de los factores de credibilidad y temas de interés que los candidatos abordan en Twitter antes y después del gran debate electoral de cada campaña. Sin embargo, se ha completado el contexto de percepción ofrecido por la red de microblogging, con los datos disponibles de las encuestas previas a ambas citas electorales, así como con la realización de dos grupos de discusión; éstos últimos han servido para una mejor comprensión de la formación de los juicios sobre credibilidad de la fuente en el público más familiarizado con las redes sociales: Las personas jóvenes.

\section{Los efectos de las campañas electorales, a estudio}

Las campañas electorales proporcionan a los votantes información clave sobre las posiciones de los candidatos, descubriendo cuáles sus valores fundamentales y el peso que dan a cada asunto público (Gelman y King, 1993: 449). Su influencia sobre la decisión de voto está contrastada por investigaciones como la de Norris et al. (1999) sobre las elecciones británicas de 1997. Sus análisis revelaron una gran volatilidad de la intención de voto durante todo el año previo al día de las elecciones, resultando aparentemente más efectivas aquellas campañas realizadas en tono positivo. Respecto al papel de los medios de comunicación en las campañas, a pesar de que proporcionan a los candidatos plataformas 
desde las que compartir sus valores y puntos de vista (Gelman y King, 1993), se viene observando una desconexión entre los asuntos que éstos destacan en periodo electoral, y los que el público considera realmente importantes (Miller, 1991: 249).

En los últimos tiempos, los investigadores albergan pocas dudas sobre la cada vez mayor complejidad de las campañas electorales:

"el aumento de las campañas posmodernas, caracterizadas por unos medios más autónomos y fragmentados, estrategias de comunicación más profesionalizadas por parte de los partidos y un electorado más delimitado, crea nuevos retos para la comunicación efectiva entre políticos y votantes en una democracia mediada". (Norris et al., 1999: 186)

Esta mayor complejidad también se aprecia en su recepción y procesamiento. Tradicionalmente, se consideraba que las campañas electorales podían provocar tres grandes tipos de efectos (Zaller, 1992): los de refuerzo, con los que se asegura el voto del elector que ya tenía pensado dar su confianza al partido en cuestión; los de activación, cuando la campaña logra que quien pensaba abstenerse acuda a las urnas; y los de conversión, si la campaña conseguía que un elector votase a un partido distinto del que tenía previsto en un principio. Tras describirlos, Zaller añadía el efecto de desactivación, si la campaña logra desmovilizar al electorado que pensaba ir a votar a un partido adversario. Pero, además, en los últimos tiempos se han distinguido los efectos de tipo persuasivo, referidos a las motivaciones, actitudes y aceptación del mensaje (Shaw, 1999), de los efectos movilizadores, los cuales constituyen la transformación de las predisposiciones de los electores en votos (Holbrook y McClurg, 2005).

Para obtener las claves sobre los efectos de los mensajes, se debe recurrir a la Psicología Social. Así, la teoría de la disonancia cognitiva (Festinger, 1957) afirma que los individuos persiguen el equilibrio cognitivo: si una información les resulta disonante con sus propias concepciones, se verán motivados para buscar la que les permita resolver ese conflicto de percepciones. Este proceso de percepción selectiva se recoge en el modelo de los efectos limitados (Klapper, 1960, en Knobloch-Westerwick y Mena, 2009: 427), ya que éste último establece que los individuos persiguen reforzar sus actitudes previamente existentes, exponiéndose a mensajes que sean consistentes con ellas. De esta manera, evitan recibir puntos de vista alternativos. Por lo tanto, según el modelo de los efectos limitados, las campañas electorales logran fundamentalmente efectos de refuerzo de las posiciones 
previas, pero no su cambio: "el refuerzo ha sido declarado el efecto dominante de la comunicación política de masas. Y la exposición y percepción selectivas son los conceptos que normalmente se usan para explicar este resultado” (McCombs y Shaw, 1972: 174).

Sin embargo, en las últimas décadas la mayor parte de los estudios han defendido la existencia de efectos amplios de las campañas electorales sobre el voto. Graber (1980) fue pionera al señalar el creciente poder de los medios sobre el resultado de las elecciones; es decir, sobre el comportamiento electoral. La política mexicana ha brindado una serie de oportunidades de estudio de estos efectos: Valenzuela y McCombs (2007) constataron que, aproximadamente, la mitad de los cambios en la decisión de voto para las elecciones presidenciales de 2000 se debió a la mayor y más positiva cobertura mediática para los candidatos de la derecha. Por su parte, Lawson y McCann (2005) comprobaron cómo la cobertura del canal TVAzteca en esos mismos comicios influyó fuertemente en la imagen negativa del candidato del PRI entre el público, frente a sus adversarios. Lawson (2002) ya había detectado la relación directa entre la exposición a Televisa y una menor probabilidad de votar por el PRI.

Del mismo modo, frente a la idea inicial de que los públicos sólo se exponen a un número limitado de fuentes similares, Magalhaes (2007: 208) defiende que los ciudadanos tienden a adquirir la información electoral de un número de agentes que, si bien es limitado, está compuesto por fuentes variadas. Defiende además que la identificación del votante con un partido representa un marco para interpretar la información política, que a su vez se traduce en una influencia estabilizadora sobre su comportamiento electoral: cuanta más identificación, menor variabilidad en el voto. Sin embargo, Dalton, McAllister y Wattenberg (2000) observaron que la alineación de los ciudadanos con los partidos es cada vez menor, lo que ha provocado que las decisiones de voto dependan mucho más de la presentación de los temas y los candidatos en las campañas. A pesar de todo, Dalton (2014: 141-142) observa que tres quintas partes de los votantes alemanes siguen identificándose con un partido, aunque continúen creciendo los que no se sienten alineados. Éstos últimos se inclinan mucho más por juzgar a los partidos en función de sus campañas, y cambiar su intención de voto a lo largo de ellas. 


\section{Twitter como la principal red social política}

En los últimos tiempos, las campañas electorales se han desplazado progresivamente hacia el entorno digital, lo que ofrece un nuevo potencial para que los líderes políticos se relacionen con el electorado (Castells, 2006).

La llegada de las redes sociales ha abierto todo un debate sobre el papel de la exposición selectiva en estas plataformas. Desde la posición de Messing y Westwood (2012), los usuarios de redes sociales priorizan el valor social que para ellos tienen los perfiles a los que siguen, por encima de los vínculos ideológicos. En consecuencia, aunque cada persona pueda mantener su exposición selectiva a webs de noticias y medios convencionales, la situación en redes sociales desembocaría en toda una diversidad de fuentes, por lo que la exposición selectiva se vería drásticamente reducida. En cambio, el estudio de Vera Liao y Fu (2013) sobre exposición en redes sociales arrojó que, incluso cuando a los sujetos se les presentaban dos puntos de vista opuestos, se decantaban preferentemente por la información que reforzaba sus actitudes. De hecho, cuando el tema era de más importancia para ellos o percibían una amenaza en relación con él, se resistían todavía más a las opiniones divergentes.

De entre todas las redes sociales hoy en día disponibles, se ha hecho patente cómo los partidos y candidatos tienden a conceder más relevancia a la red de microblogging Twitter que a otras alternativas, como Facebook (Chaves-Montero y Gadea-Aiello, 2017: 13). Ello se debe a que Twitter proporciona una plataforma tanto a políticos como a grupos de interés, instituciones y ciudadanos, para la comunicación entre ellos y la difusión de contenidos de forma "simultánea, diferenciada, retransmitida y recibida por todas las partes" (CamposDomínguez, 2017: 786).

Desde el ámbito académico, ya existen experiencias en las que se han utilizado los registros de redes sociales para realizar ejercicios de monitorización de la marcha diaria de campañas electorales (Jensen y Anstead, 2013; Wang et al., 2012), pero tienden a centrarse en la recogida de opiniones y sentimientos de los usuarios. De forma similar, Bermingham y Smeaton (2011) llevaron a cabo un análisis de las menciones a los cinco principales partidos que se presentaron a las elecciones generales irlandesas, registrando tanto los volúmenes de tuits como si éstos reflejaban un sentimiento negativo o positivo hacia cada formación. Por su parte, Effing, van Hillegersberg y Huibers (2011) aplicaron un nuevo estándar para recoger el grado de participación e interacción de un político en estas plataformas: El 
Indicador de Redes Sociales (Social Media Indicator, SMI). Esta herramienta sirvió para comprobar cómo, en elecciones generales, se daba una correlación entre la intensidad del empleo de las redes sociales por cada candidato, y su número de votos.

Otras investigaciones han sido dedicadas al análisis de la producción comunicativa de los candidatos electorales en Twitter; y, por fortuna para el propósito que nos ocupa, entre ellas figuran notables ejemplos del panorama político español. Tras las elecciones generales de 2011, García Ortega y Zugasti (2014: 301-307) analizaron los temas y la bidireccionalidad de los tuits lanzados en campaña por los candidatos Mariano Rajoy y Alfredo Pérez Rubalcaba, arrojando un nivel de conversación moderado por parte de estos líderes y centrado principalmente en la interacción con los ciudadanos. Se trata de un resultado que hasta cierto punto contrasta con los hallazgos sobre las cuentas del Partido Socialista Obrero Español (PSOE) y el partido emergente Podemos en las elecciones europeas de 2014, cuando la interacción con sus seguidores fue escasa y primó la mantenida con representantes de las propias formaciones políticas estudiadas (Casero-Ripollés, Miquel-Segarra y AlonsoMuñoz, 2016: 5). Esta observación respecto a las elecciones europeas no es exclusiva para los perfiles de las organizaciones, sino que también fue notorio cómo la mayor parte de los candidatos adoptaron un enfoque endogámico en redes sociales, al limitarse a mencionar e interactuar con las cuentas de los propios partidos o grupos institucionales en los que participaban (Gelado y Bonete-Viscaíno, 2018: 278). Incluso en las elecciones generales de 2015 que nos ocupan, el análisis de Chaves-Montero, Gadea-Aiello y Aguaded-Gómez (2015: 77-78) destaca la unidireccionalidad de la comunicación de Mariano Rajoy y Pedro Sánchez en redes sociales, y un mayor grado de bidireccionalidad en las cuentas de Pablo Iglesias y Albert Rivera, con tasas de participación claramente superiores para estas últimas formaciones.

Por su parte, Quevedo Redondo et al. (2016: 90-93) emplearon una muestra de 36 candidatos a las elecciones municipales de 2015, extrayendo de ella datos cuantitativos como el número de retuits y las veces que los mensajes habían sido marcados como favoritos y combinándolos con un análisis de contenido de los mensajes. Aunque, con motivo de las elecciones europeas de 2014, los nuevos partidos comprendieron mejor el formato interactivo de las redes sociales frente al planteamiento unidireccional de las formaciones tradicionales (Gelado y Bonete-Viscaíno, 2018: 278), persisten en las cuentas de Twitter continuas referencias a las intervenciones de los líderes políticos en medios generalistas:

Perspectivas de la Comunicación - Vol. 13 - No 2 - 2020 - pp. 105-151

Universidad de la Frontera - Chile 
[...] no sólo se verifica el supuesto inicial de este estudio, basado en la hipótesis de que los líderes dotan de un carácter indicial predominante a los elementos visuales para evocar la figura del profesional que está en contacto con la calle y en permanente servicio al bien común, sino que se observa un afán por encauzar el interés de los followers hacia los tradicionales espacios de comunicación de masas. (Quevedo Redondo, Portalés-Oliva y Berrocal Gonzalo, 2016: 103)

Ya centrándose en las campañas digitales para las elecciones generales de 2015 y 2016, Dader y Campos-Domínguez (2017) comprobaron que las dinámicas no mejoraron para dichos comicios; estos autores concluyeron que los candidatos y partidos se sirvieron de Twitter como herramienta básicamente propagandística y viralizadora, dedicándose a la autopromoción de sus propias propuestas y contenidos. Sólo buscaron un efecto multiplicador e instantáneo para su mensaje, tendiendo una vez más a la unidireccionalidad. En una línea similar se expresó López-García (2016) al analizar la actividad en Twitter de los cuatro principales candidatos en las generales de 2015 y comprobar las diferencias entre el uso que le daban los partidos emergentes, que se centraron en enviar mensajes de movilización para sus seguidores, vaticinar su victoria y vincularse a la idea de cambio; y el ejercido por PP y PSOE, más centrados en la difusión de sus propuestas programáticas. Del mismo modo, al analizar el uso de Twitter en la campaña de 2016, López-Meri, MarcosGarcía y Casero-Ripollés (2017) observaron la formulación de propuestas como la principal función para la que los actores políticos emplearon Twitter, seguida de la personalización y la hibridación con medios convencionales.

\section{Debates electorales y nuevas formas de verlos}

Las retransmisiones televisivas son sistemáticamente los eventos que más volumen de tuits generan a nivel mundial (Deltell, 2014: 34), llegando al extremo en el que las redes sociales se convierten en "una forma de retransmitir lo que se está viendo en la televisión, ya sea antes, después o durante el visionado" (Lorente-Cano, 2011: 57); esto se debe, en gran medida, al uso de etiquetas o 'hashtags' creados para agrupar los mensajes sobre un programa televisivo determinado (Harrington, Highfield y Bruns, 2013). De esta manera, los grandes medios tradicionales tratan de adaptar cada vez más sus contenidos al entorno digital en el que son consumidos; un entorno en el que todos los actores se encaminan hacia la creación de espacios políticos híbridos desde el punto de vista mediático (Chadwick, 2013), con una relación directa entre los comentarios en Twitter y el seguimiento de formatos televisivos tradicionales. Naturalmente, los candidatos más influyentes en redes son quienes mejor saben aprovechar dicho vínculo (Karlsen y Enjolras, 2016: 352). 
Dentro de las retransmisiones por televisión, aunque los debates electorales sean una de las herramientas de comunicación política más exigentes, sin duda constituyen una oportunidad para que el candidato demuestre que se preocupa por los mismos problemas que los electores. Así, los efectos de los debates han generado un gran interés entre los académicos. Si nos centramos en los efectos de los debates electorales, Geer (1988) fue el primer investigador que suavizó la asunción tradicional tajante de los efectos limitados para este tipo de formatos. Tras analizar una serie de encuestas durante la campaña electoral de las elecciones presidenciales estadounidenses, comprobó que los debates podían cambiar las preferencias de los votantes indecisos o débilmente inclinados por alguno de los contendientes.

En cualquier caso, la mayoría de los estudios concluyen que los debates electorales tienen un impacto limitado en la intención de voto, logrando influir fundamentalmente en la de los votantes indecisos, y marcando una mayor diferencia cuanto más abiertas y reñidas estén las elecciones entre los candidatos (Pfau, 2002; McKinney y Warner, 2013). En una serie de grupos de discusión, Coleman y Moss (2016: 11) preguntaron a los espectadores qué era lo que esperaban conseguir al ver un debate electoral: Los actuantes tendieron a explicar que los debates les permitían observar a la persona real detrás del político, en un formato que les podía llevar a mostrarse tal y como eran. Otra investigación, llevada a cabo por Benoit y Hansen (2001: 136-140), puso de manifiesto la enorme distancia que existía entre las preguntas formuladas por los periodistas que moderaban un debate electoral, y los asuntos que realmente resultaban de interés público, de acuerdo con los propios votantes.

No obstante, si bien los públicos reconocen que no suelen encontrar suficientes elementos para determinar quién tiene razón durante un debate electoral, éstos se revelan como un recurso clave para que los votantes emitan juicios sobre la credibilidad de los candidatos, puesto que en el estudio de Coleman y Moss (2016: 13) tendían a criticar las incoherencias de los políticos entre lo que decían en el debate y lo que habían hecho en el pasado. En esta tesitura, no es de extrañar que las actuales prácticas de verificación de hechos en redes sociales (conocidas como fact-checking) estén ayudando a los electores a atribuirles honestidad o deshonestidad, aumentando la inclinación por votar a aquel que resulta más sincero (Wintersieck, 2017: 304). Desde el punto de vista de los candidatos como emisores, Mazaira-Castro, Rúas-Araújo y Puentes-Rivera (2019: 748) hallaron una elevada exactitud en los datos utilizados en los debates electorales por los candidatos a las elecciones generales 
de 2015 y 2016 en España, si bien algo inferior para el candidato del PSOE, Pedro Sánchez; y ello a pesar de que en general se echó de menos que citaran las fuentes de las que procedían. En el estudio de los debates electorales televisados, el nuevo vínculo de Twitter con la televisión ha dado lugar a la introducción del concepto de la doble pantalla: "El complejo conjunto de prácticas que implican la integración, y la conexión a través y entre ellas, de las emisiones de medios en directo y las redes sociales" (Vaccari et al., 2015: 1041). Es más, en el caso del debate de abril de 2014 entre dos líderes de fuerzas políticas británicas ante las elecciones europeas, fueron más los usuarios que leyeron acerca del debate en Twitter que los que formaban parte de la audiencia televisiva del mismo; y un considerable $29 \%$ de los encuestados se sumó a ésta última tras leer algún comentario en la red social (Vaccari, Chadwick y O’Loughlin, 2015: 1050).

En España, en el año 2015, los debates electorales del 7 y el 13 de diciembre fueron los dos programas más comentados en Twitter de todo el año, y sólo el Festival de Eurovisión se acercó a sus cifras, poniéndose por delante del debate a dos del 13 de diciembre en el número de comentarios publicados durante el tiempo de emisión del espacio (Kantar Media, 2016: 7). Este debate también marca un antes y un después en la comunicación política española, al celebrarse por primera vez con varios periodistas como moderadores, y colocar a los candidatos de cara a ellos en vez de a otro rival (Ruiz-del-Olmo y Bustos-Díaz, 2016: 249). Los distintos debates electorales llevados a cabo con motivo de las elecciones generales de 2015, permitieron a los candidatos plantear propuestas políticas con un menor grado de mediatización que en otros momentos de la campaña, si bien los formatos mediáticos que se alimentaron de aquellos debates volvieron a incidir en cuestiones como el desarrollo de la campaña, la personalidad de los candidatos e incluso la actividad que generaron en redes sociales (López-García et al., 2018: 790-791).

\section{La credibilidad, factor clave de la imagen del político}

Si se observan los aspectos sobre la comunicación política que más interés vienen suscitando, uno de los puntos fundamentales es el grado en el que un candidato resulta creíble para la audiencia.

La variable de la credibilidad fue ampliamente descrita por el psicólogo social Carl Hovland y sus compañeros de la conocida como Escuela de Yale. En concreto, establecieron que la credibilidad de la fuente dependía en gran medida de la aceptación del portavoz por parte del público, lo que significaba que, por encima de todo, constituía un juicio particular del 
receptor (Hovland, Janis y Kelly, 1953; Hovland y Weiss, 1951). Los miembros de la audiencia atribuían credibilidad a la fuente atendiendo especialmente al conocimiento experto y la confiabilidad que percibían en ella (Hovland, Janis y Kelly, 1953), una forma de abordarla en los estudios sobre comunicación que se ha mantenido estable a lo largo del tiempo (Metzger et al., 2003; Sternthal, Dholakia y Levitt, 1978).

En la actualidad, para Berrocal (2004: 61), "la credibilidad es la piedra de toque de la persuasión, condición sine qua non para tener éxito en la comunicación de un mensaje. Un mensaje apropiado, atractivo y coherente comunicado por un portavoz de escasa credibilidad carece de eficacia”. Cuando este planteamiento se aplica a la comunicación política, la credibilidad acaba siendo entendida como "un activo crucial para los líderes políticos y es clave para comprender el fracaso y el éxito en el competitivo mercado político" (Van Zuydam y Hendriks, 2018: 258). Por otra parte, la credibilidad del mensaje es en sí misma otra variable que interactúa con la de la fuente; en ello entran en juego la familiaridad con los contenidos del mensaje, su repetición o el orden en el que sus elementos son dispuestos (Boehm, 1984).

Centrándonos de nuevo en la credibilidad de la fuente, ésta constituye el elemento más importante para determinar las creencias por las que el púbico se construye su propia imagen sobre los líderes políticos; así la clasifica el catedrático de Comunicación Política José Luis Arceo (1993), basándose en los trabajos de Hovland y Weiss (1951), Hovland, Janis y Kelly (1953), Iyengar y McGuire (1995), Lasswell (1974), Lau y Sears (1986), McGuire (1969; 1972; 1985), Newman (1999), Kaid (2004) y West y Turner (2004), entre otros muchos. De acuerdo con Arceo (1993: 18), el análisis debe atender a las siguientes variables: El conocimiento experto que el público atribuya a la fuente; la fiabilidad ética que se le reconozca, la cual también contiene las percepciones acerca de los intereses por los que un candidato participe en política; y la eficacia social, referida al dinamismo del candidato, el grado en que éste realiza propuestas, se preocupa por los problemas existentes y acomete acciones.

No obstante, al hablar de factores de tampoco se puede pasar por alto el atractivo del candidato. En este sentido, "la apariencia del candidato importa más cuando las elecciones se centran en candidatos individuales, en vez de en partidos, y cuando los costes de adquirir información sobre los candidatos son altos" (Lawson et al., 2010: 562). Hasta tal punto puede llegar la influencia del atractivo que, según Todorov et al. (2005: 1623), "las 
inferencias sobre competencia, basadas únicamente en el aspecto facial de los candidatos políticos y sin ningún conocimiento previo sobre la persona, predicen los resultados de las elecciones para el Congreso de EE.UU.”. De hecho, junto a la credibilidad, José Luis Arceo establece otros dos factores de imagen aplicables a un candidato político: El atractivo y el poder, cada uno de ellos compuestos a su vez por otros tres subfactores (Arceo, 1993: 18). Para Arceo, la atribución de poder por el público se basa en el estatus o la capacidad del político para imponer sus decisiones, los apoyos sociopolíticos o económicos que tenga y el interés que muestre por las opiniones de los ciudadanos; el atractivo, en la notoriedad del candidato, su similitud sociodemográfica con miembros del público y su estilo de vida.

\section{El enmarcado como condición para la credibilidad}

Durante un debate electoral, los candidatos tienen que demostrar que se preocupan por los problemas de los electores, por lo que aprovechan para explicar sus propuestas políticas en un formato que les proporciona un menor grado de mediatización (López García et al., 2018: 790). De lo contrario, pueden caer en las diferencias que tienden a existir entre los temas planteados por los moderadores y los que realmente interesan a la audiencia (Benoit y Hansen, 2001: 136-140). Para ello, merece la pena tener en cuenta el potencial de la teoría del framing o enmarcado, la cual puede pasar de ser un paradigma teórico de la comunicación social a convertirse en una herramienta de comunicación estratégica. Los políticos no pueden ignorar los marcos de referencia con los que la audiencia realiza sus operaciones cognitivas, porque éstos condicionan la forma en que sus integrantes interpretan la información que les llega (Pan y Kosicki., 2001).

La teoría del enmarcado traslada a la investigación en comunicación una formulación original de Erving Goffman, quien utiliza el término inglés frame (traducible como un marco o una estructura subyacente) para denominar a "los principios de organización que gobiernan los acontecimientos -al menos los sociales- y nuestra implicación subjetiva en ellos" (Goffman, 1974: 10-11). Es decir, los marcos constituyen unas estructuras básicas de entendimiento que permiten a los individuos definir de forma negociada las situaciones de interacción en las que participan. Ante la multitud de aplicaciones del framing en comunicación social y la dificultad para cohesionarlas en un mismo cuerpo teórico, Robert Entman trató de sintetizarlas mediante la descripción de la acción de enmarcar en el ámbito del periodismo como: "Seleccionar algunos aspectos de la realidad percibida y hacerlos más salientes en un texto comunicativo, de manera que se promueva una definición del problema 
particular, interpretación causal, evaluación moral, y/o recomendación de tratamiento para el ítem descrito" (Entman, 1993: 52).

Ahora bien, ¿cómo puede ser útil la teoría del enmarcado en el campo específico de la comunicación electoral? Para George Lakoff (2007: 4), los 'frames' tienen que entenderse como estructuras mentales que condicionan nuestras perspectivas sobre el mundo, traduciéndose en políticas públicas y en las instituciones políticas que se hacen cargo de aplicarlas. Si unos hechos no encajan con el marco activado en la mente de una persona, de entrada serán ignorados por ésta (Lakoff y Wehling, 2016: 85). Lakoff habla además de unos frames superficiales, que se encuentran asociados directamente a determinadas palabras que los activan en las mentes de los individuos, pero que necesitan encajar con unas estructuras superiores de entendimiento del mundo; por ello recomienda a los políticos progresistas la activación de marcos que expresen fielmente sus puntos de vista morales (Pinker y Lakoff, 2007: 67). Más recientemente, Lakoff (2013: 61-72) renombra sus conceptos habituales para referirse a marcos profundos (basados en unos valores compartidos) y marcos argumentales, los cuales parten de los primeros para elaborar razonamientos sobre alguna cuestión de interés.

En esta misma línea, si bien más alejados de la lingüística y más próximos a la sociología interpretativa original, Pan y Kosicki (2001: 59) entienden el enmarcado como "una forma discursiva de lograr potencia política influyendo en la deliberación pública”. Es decir, que los candidatos electorales, al igual que cualquier otro agente que busque compartir con sus públicos la definición de una situación, deberán destacar determinados aspectos de su discurso para evocar en sus potenciales votantes los esquemas interpretativos deseados sobre un tema. Sin embargo, a la hora de acometer esta táctica, necesitarán tener presente que compiten con las definiciones de la situación de sus rivales, con los esquemas mentales que posean los públicos de antemano, y con los encuadres de los medios o media frames. Este último escenario entraña algunos nuevos riesgos para los candidatos electorales:

[...] que el enmarcado de las noticias puede eliminar voces y debilitar argumentos, que los medios pueden enmarcar cuestiones de maneras que favorezcan a una parte en particular sin mostrar una parcialidad explícita, y que definir los términos de un debate lleva a uno a recorrer un largo trecho hacia ganarlo (Tankard, 2001: 96).

Perspectivas de la Comunicación - Vol. 13 - No 2 - 2020 - pp. 105-151

Universidad de la Frontera - Chile 
En el ámbito hispanoamericano, Chihu (2008: 92-95) aplicó específicamente la teoría del enmarcado a los debates presidenciales mexicanos, describiendo una serie de campos de identidad resultantes de los diferentes tipos de marcos a los que los candidatos recurren para movilizar: El campo de identidad de los protagonistas les sirve para definirse a sí mismos, y el de los antagonistas para definir a los adversarios. Y es que el papel de los medios no obsta para que las fuentes políticas con un alto grado de credibilidad tengan más probabilidades de conseguir que las audiencias acepten sus marcos de referencia. La credibilidad de la fuente constituye un prerrequisito para tener éxito en el enmarcado de los asuntos públicos (Druckman, 2001: 1061), lo que a su vez implica que las audiencias tienen capacidad para aceptar unos marcos propuestos por las fuentes y rechazar otros. Recurriendo a una perspectiva cognitivista para comprender esta dinámica: Cuando las evidencias proporcionadas sobre una afirmación son ambiguas, la credibilidad de la fuente se convierte en un factor para el procesamiento sistemático de información que el receptor percibe como importante (Chaiken y Maheswaran, 1994: 470). En otras palabras: La credibilidad de la fuente actúa como un heurístico que interfiere con la elaboración cognitiva, con el procesamiento de unos argumentos persuasivos.

En los últimos tiempos, los medios tradicionales ya no están solos a la hora de ayudar a que los públicos adquieran información sobre candidatos o partidos políticos. Las redes sociales han transformado los parámetros por los que el público atribuye credibilidad, dado que los nuevos entornos de comunicación online tienen un especial impacto en las atribuciones de conocimiento experto y fiabilidad; y ello en unos tiempos en los que los espectadores necesitan dilucidar la credibilidad de una mayor cantidad de fuentes distintas (Metzger y Flanagin, 2013: 210-212). Incluso en los inicios de las redes sociales, el 52 \% de los jóvenes encuestados por Smith y Boyles (2012: 2) reconocían que solían ver la televisión al mismo tiempo que navegaban por Internet con su smartphone, reproduciendo la práctica de la segunda pantalla.

En suma, de toda esta revisión teórica se desprende que, para que un candidato consiga que sus votantes potenciales acepten los marcos que les propone, necesita en primer lugar que le perciban como creíble. Para ello, deberá tratar de esforzarse por transmitir su conocimiento experto, su honestidad y su eficacia social. Pero no le bastará con volcarse en el debate puesto que, en nuestros días, los contenidos de las redes sociales condicionan considerablemente tanto las atribuciones de credibilidad como la forma de consumir televisión. 


\section{Metodología}

El objeto formal de la presente investigación es el papel de los perfiles que los candidatos políticos poseen en Twitter, en la generación del contexto de percepción de los debates electorales. Esta cuestión se aborda desde la perspectiva de la comunicación política, recurriendo a teorizaciones sobre las variables de credibilidad y los factores de imagen que se nutren del conocimiento acumulado en Psicología Social. Este objeto formal se concreta en el seguimiento de los diferentes subfactores de credibilidad para los candidatos de las elecciones generales de 2015 y 2016 en España. Igualmente, se pretende además observar los posibles esquemas empleados por el público joven, principal usuario de redes sociales, para valorar la credibilidad de los candidatos durante los debates electorales.

Aunque el diseño es eminentemente cuantitativo, se ha introducido la técnica cualitativa del grupo de discusión para contribuir a la comprensión de los datos estadísticos. De esta manera, se aplica un método inductivo con el que obtener conclusiones sobre las campañas objeto de estudio, partiendo de un conjunto de datos específicos.

\section{Análisis de encuestas electorales y de opinión}

Teniendo presentes los comentarios de Diakopoulos y Shamma (2010: 1198), quienes advierten contra la idea de sustituir las encuestas adecuadamente diseñadas por cualquier método de análisis de tuits, se acudió a los sondeos correspondientes a las dos campañas electorales analizadas. Se pretende así obtener una mejor comprensión del contexto de percepción en el que tuvieron lugar los debates electorales, mediante el análisis de las correlaciones entre los resultados de una serie de encuestas publicadas por los principales centros demoscópicos españoles, durante los dos meses previos a cada cita electoral. Se han escogido estos periodos porque el volumen de encuestas realizadas es lo suficientemente grande como para extraer datos relevantes; y porque consideramos que su proximidad a los respectivos comicios las hacen válidas para observar las tendencias que se dieron entre los votantes potenciales.

A la hora de determinar qué encuestas debían formar parte de esta revisión, se escogieron las de dos instituciones: Por un lado, las de Metroscopia, por ser en aquel momento la empresa demoscópica de referencia para el periódico "El País", principal diario impreso español; por otro, los estudios poselectorales del Centro de Investigaciones Sociológicas CIS, un organismo público dependiente del Ministerio de la Presidencia. Para una mejor

Perspectivas de la Comunicación - Vol. 13 - No 2 - 2020 - pp. 105-151

Universidad de la Frontera - Chile 
contextualización de los datos que proporcionaron estos estudios, se ofrecen las principales características de sus fichas técnicas (Tabla 1).

Tabla 1. Fechas de realización, muestras (número de entrevistas) y márgenes de error (\%) de las encuestas de Metroscopia y el CIS

\begin{tabular}{|l|l|l|l|l|}
\hline & \multicolumn{2}{|c|}{ Metroscopia } & \multicolumn{2}{c|}{ CIS postelectorales } \\
\hline & $\begin{array}{l}\text { Diciembre } \\
2015\end{array}$ & Junio 2016 & $\begin{array}{l}\text { Enero-marzo } \\
2016\end{array}$ & Mayo 2016 \\
\hline Fechas & $\begin{array}{l}7-10 \text { de } \\
\text { diciembre }\end{array}$ & $\begin{array}{l}31 / 05^{-} \\
\text {01/06 }\end{array}$ & 07/01-19/031 & 2-21 de julio \\
\hline $\begin{array}{l}\text { Muestr } \\
\text { a }\end{array}$ & 2.800 & 1.200 & 6.242 & 6.175 \\
\hline $\begin{array}{l}\text { Margen } \\
\text { de error }\end{array}$ & \pm 1.9 & \pm 2.9 & $\pm 1,3$ & $\pm 1,3$ \\
\hline
\end{tabular}

Fuente: Metroscopia.org y CIS (2016a, 2016b).

En los estudios de Metroscopia se ha atendido a los siguientes datos disponibles: la confianza en los candidatos y su consiguiente evaluación como líderes; cuáles eran los problemas que más preocupan a los ciudadanos, y cómo esto último pudo interaccionar con su intención de voto. Por su parte, los estudios postelectorales del CIS se han empleado para recoger el seguimiento de los debates tomados como referencias, y las impresiones de los encuestados sobre la actuación de los candidatos en ellos.

\section{Grupos de discusión}

Para recoger opiniones directas que permitieran un mejor entendimiento acerca de cómo la gente realiza juicios sobre la credibilidad de las fuentes, se llevaron a cabo dos focus groups, cada uno de ellos con seis componentes. Tal y como la describen Gaitán y Piñuel (2010: 122), el focus group es "una técnica cualitativa de reunión de grupo que permite tener un conocimiento aproximado de la realidad social que se pretende investigar, mediante la comunicación que se produce en su seno”.

Naturalmente, la aplicación de esta técnica no pretendió extraer conclusiones acerca de los juicios de credibilidad que los públicos realizaran durante los debates de 2015 y 2016, sino conseguir una orientación general acerca de cómo actúan estos procesos cognitivos, al 
recabar los elementos que los propios participantes reconocen como claves en sus evaluaciones de los candidatos.

Con los objetivos de la presente investigación en mente, se procedió a un muestreo de conveniencia, seleccionando a una serie de actuantes con disponibilidad para tomar parte y con la condición de que perteneciesen a la población joven, dada su mayor participación en redes sociales y tendencia a la doble pantalla (Smith y Boyles, 2012). En el primer grupo de discusión celebrado participaron cuatro mujeres de 22 años de edad, una mujer de 19 años y un hombre de 22, todos estudiantes desempleados o sin ocupación. Todos poseían estudios superiores salvo la mujer de 19 años, que todavía los estaba cursando. En este grupo, cuatro personas habían votado a Ciudadanos el 20 de diciembre de 2015, y una al PSOE (la mujer más joven no tenía aún derecho a voto). Para las elecciones de junio de 2016, tres votaron al PSOE y dos mantuvieron su voto a Ciudadanos.

Por su parte, el segundofocus group conducido contó con la presencia de cuatro mujeres de 22 a 29 años de edad, un hombre de 27 años y un hombre de 29. Todos contaban con un título universitario, y cinco de ellos trabajaban en el momento de realizar la dinámica (noviembre de 2018). En este caso, entre los participantes había cuatro votantes de Podemos y dos de Ciudadanos en diciembre de 2015; para junio de 2016, tan solo un actuante optó por emitir un voto nulo en vez de seguir otorgando su confianza a Unidos Podemos. En ambos grupos, todas las personas eran residentes en la Comunidad de Madrid, si bien en el primero había otras procedencias tan diversas como las provincias españolas de Badajoz, Córdoba, Asturias y Murcia.

Ambas dinámicas comenzaron con la proyección de un fragmento del debate entre los cuatro candidatos a la presidencia del Gobierno, celebrado el 14 de junio de 2016. En él, uno de los moderadores les preguntaba qué harían para evitar una segunda repetición de las elecciones. Éste era un tema candente, puesto que la fragmentación política había llevado al bloqueo para la formación de un gobierno.

A continuación, el dinamizador de los grupos siguió un guión abierto para fomentar el debate entre los actuantes. De acuerdo a dicho guión, fueron preguntados por sus impresiones sobre el conocimiento experto, la fiabilidad ética y la eficacia social de los 
diferentes líderes; igualmente, se fomentó la conversación acerca de lo que para ellos convertía a un candidato en creíble (Tabla 2).

Tabla 2. Contenido de los grupos de discusión.

\begin{tabular}{|l|l|}
\hline 1. & Impresión general sobre los candidatos (asunto introductorio). \\
\hline 2. & Grado de importancia concedido a las campañas. \\
\hline 3. & Conocimiento experto de los candidatos. \\
\hline $4 \cdot$ & Grado de acuerdo con las declaraciones de los candidatos. \\
\hline 5 & Credibilidad de los candidatos como fuentes. \\
\hline 6. & Fiabilidad de los candidatos. \\
\hline 7. & Sinceridad de los candidatos. \\
\hline 8. & $\begin{array}{l}\text { Factor de precisión en la credibilidad del mensaje (Metzger et. al., } \\
\text { 2003). }\end{array}$ \\
\hline
\end{tabular}

Fuente: Elaboración propia.

Siguiendo las pautas de la teoría fundamentada socioconstruccionista (Charmaz, 2006), se procedió a analizar las transcripciones con ayuda del software de análisis cualitativo Atlas.TI. De esta manera, se practicó una reflexión continua sobre los datos extraídos, categorizándolos y valorando sus posibles relaciones, hasta que se detectó el alcance de la saturación teórica sobre los marcos mentales con los que el público joven percibe la credibilidad de un candidato electoral.

\section{Análisis de contenido de perfiles en Twitter}

De acuerdo con la síntesis de Arceo (1993: 18) sobre los factores de la imagen del político, esta investigación parte de la hipótesis de que los candidatos a la presidencia del Gobierno tuvieron que recurrir en Twitter a los diferentes subfactores de credibilidad para generar un contexto de percepción favorable durante las campañas. En consecuencia, se han analizado los tuits emitidos desde las cuentas de los cuatro principales candidatos: @marianorajoy, @sanchezcastejon, @Pablo_Iglesias_y @Albert_Rivera. Para ello, se ha recurrido a la técnica del análisis de contenido: "un método de estudio de comunicación de forma sistemática, objetiva y cuantitativa, con el fin de medir determinadas variables" (Wimmer y Dominick, 1996: 170). Pasamos, por lo tanto, a establecer con exactitud cuáles fueron esas variables en el análisis de materiales comunicativos que nos ocupa. 
El periodo de análisis abarca desde dos semanas antes hasta una semana después de los debates electorales citados: Esto es, del 1 al 20 de diciembre de 2015, y del 30 de mayo al 19 de junio de 2016. Se han escogido estas fechas para contar, por un lado, con el contexto y los mensajes de campaña previos a los debates escogidos; por otro, se recogen las posibles variaciones de dichos aspectos en los días posteriores a cada debate televisado de referencia. Una vez que se definieron las fechas indicadas, no se procedió a muestreo alguno, sino que se han analizado la totalidad de los tuits publicados (es decir, "n" es igual a "N", a toda la población). Se analizaron 2.387 tuits de la campaña de 2015, y 2.497 de junio de 2016 (Tabla 3).

Tabla 3. Totales de tuits analizados.

\begin{tabular}{|l|l|l|l|l|}
\hline & Rajoy & Sánchez & Iglesias & Rivera \\
\hline $\begin{array}{l}\text { Del 30/11 al 14/12 de } \\
2015\end{array}$ & 672 & 433 & 186 & 396 \\
\hline Del 15 al 20/12 de 2015 & 208 & 293 & 71 & 149 \\
\hline $\begin{array}{l}\text { Del 30/05 al 13/06 de } \\
2016\end{array}$ & 407 & 454 & 147 & 429 \\
\hline $\begin{array}{l}\text { Del 13 al 20/06 de } \\
2016\end{array}$ & 367 & 300 & 48 & 345 \\
\hline
\end{tabular}

Fuente: Elaboración propia.

El corpus de análisis también incluye los retuits efectuados por los candidatos desde sus respectivas cuentas, salvo para aquellos días comprendidos en el periodo de análisis en los cuales los sistemas de métricas empleados no contaban con registros. Los mensajes de Twitter se han recuperado mediante el empleo del Sistema Cecubo Metrics y de la plataforma TweetDeck.

A la hora de componer el libro de códigos, la mayor parte de las categorías de análisis traducen a elementos objetivos las definiciones académicas de los factores de imagen y subfactores de credibilidad:

Competencia y conocimiento experto: Se codificó cuando el candidato demostraba dominio del tema del que hablaba, o bien evidenciaba que un adversario no lo controlaba. En concreto, la categoría registra la presentación de datos estadísticos en el tuit; el desmentido de los aportados por un contrincante; las valoraciones sobre la capacidad de gestión propia o de un rival, y el empleo de un idioma distinto a las lenguas maternas del candidato.

Perspectivas de la Comunicación - Vol. 13 - No 2 - 2020 - pp. 105-151

Universidad de la Frontera - Chile 
Fiabilidad ética: Hincapié del candidato en su propia honestidad y limpieza, o cuestionamiento de la de un adversario; alusión a compromisos suyos o de otros candidatos (para lo cual, el tuit tenía que contener explícitamente el término "compromiso" o algún otro de su familia léxica. También se registraba esta categoría si el candidato se defiende sobre la corrupción de su propio partido, o atacaba a sus adversarios por esta misma cuestión.

Dinamismo y eficacia social: Se codifica siempre que el candidato desarrolle una argumentación, lance una propuesta programática o explique cualquier principio político que guíe su proyecto. Asimismo, se registró esta unidad de análisis cada vez que el candidato animaba o bien disuadía al público de llevar a cabo una acción. También se codificaron mediante esta unidad de análisis aquellos tuits en los que el candidato aludía a cualquier actuación suya a través de alguno de los elementos del tuit (ya sea una visita, una medida política, una actividad pública o en su vida privada).

Atractivo: Presencia de cualquier fotografía o vídeo del candidato, de su partido o de sus actos públicos; muestras de su vida personal (familia, amigos) y del estilo de vida que practica (aficiones); muestras de agradecimiento a terceros, como compañeros de partido o simpatizantes; y muestras de interés por las inquietudes y opiniones del público.

Poder: Se codificará cuando el candidato difunda su capacidad de obrar, de hacer que las cosas ocurran; o cuando la acción de la que hable sea de gobierno (lo que incluye la codificación de la presencia de toda la familia léxica del verbo "gobernar"). La categoría incluye la presencia de estamentos desde los que se ejerce poder (instituciones nacionales, supranacionales, mandatarios internacionales); el registro de verbos en futuro para próximas acciones ("haremos", “cambiaremos”, "conseguiremos”, etc.), y del verbo "poder" cuando se utilice para hablar de acciones de campaña o gubernamentales.

Paralelamente, se creó un bloque temático dentro del libro de códigos, con el que se han registrado los asuntos que más presencia tenían en los tuits de los candidatos. Para fijar y definir dichas categorías temáticas, se tomaron como referencia los cuatro grandes bloques en los que se dividió el "cara a cara” entre Rajoy y Sánchez, emitido el 14 de diciembre de 2015: Economía y empleo (al que se añadió la energía y el medio ambiente a efectos de la codificación); políticas sociales; regeneración democrática (al que, en este caso, se añadieron las cuestiones territoriales), y política exterior.

Otras dos categorías adicionales contemplaron el libro de códigos y se codificaron durante el análisis del corpus de tuits: El concepto de 'ataque', definido como la emisión de una crítica o un juicio negativo contra un adversario u otro agente social (incluida toda crítica a una propuesta política o programática de un tercero); y el de 'defensa', registrado tanto si el candidato/partido contestaba a la acusación o crítica de un tercero, como si se trataba de una crítica vertida por el candidato, en este caso, como respuesta a un ataque previo de otro agente (se requería que el tuit explicitara que estaba respondiendo a algo dicho previamente por esa tercera persona u organización). Por último, se añadió una categoría con la que registrar las alusiones objetivas a alguno de los debates electorales televisados. Finalmente, 
se observaba la intensidad con la que se tenía que se debía registrar la presencia de la unidad de análisis (Tabla 3).

Tabla 3. Codificación de las categorías según su grado de presencia en el tuit.

\begin{tabular}{|l|l|}
\hline 0 & El ítem no está presente. \\
\hline 1 & $\begin{array}{l}\text { El ítem sólo se aprecia en frases que } \\
\text { no abren el tuit; en la entradilla del } \\
\text { enlace que se incluya en el tuit, o bien } \\
\text { su presencia es mínima en la imagen } \\
\text { o vídeo incluidos. }\end{array}$ \\
\hline 2 & $\begin{array}{l}\text { El ítem aparece en menciones a otras } \\
\text { cuentas o etiquetas que no abren el } \\
\text { tuit, sino que se incorporan a mitad } \\
\text { del mensaje o al final; en un titular o } \\
\text { imagen una vez se hace clic en un } \\
\text { enlace, o presencia moderada del } \\
\text { ítem en la imagen o vídeo (no más del } \\
30 \% \text { del vídeo o de la quinta parte de } \\
\text { la imagen). }\end{array}$ \\
\hline 3 & $\begin{array}{l}\text { El ítem está presente en la primera } \\
\text { frase del texto del tuit, pero no } \\
\text { protagoniza la imagen, vídeo, enlace } \\
\text { o incrustado que el mensaje también } \\
\text { incorpore; y viceversa: el ítem } \\
\text { protagoniza la imagen, vídeo, enlace } \\
\text { o incrustado, pero no se puede } \\
\text { codificar su presencia objetiva en la } \\
\text { frase que abre el tuit. }\end{array}$ \\
\hline $\begin{array}{l}\text { El ítem aparece en todos los } \\
\text { elementos del tuit. Si no contiene } \\
\text { ningún elemento multimedia, la } \\
\text { presencia delítem en la primera frase } \\
\text { del mensaje se codifica con esta } \\
\text { puntuación máxima. }\end{array}$ \\
\hline 4
\end{tabular}


Fuente: Elaboración propia.

En aras de comprobar la fiabilidad del análisis de contenido, éste se encomendó en su totalidad a dos codificadores. De acuerdo con el libro de códigos expuesto, cada uno de ellos tuvo que tomar un total de 58.860 decisiones de codificación en 4.905 tuits diferentes. Ambos codificadores coincidieron en 54.515 de esos juicios (es decir, otorgaron exactamente la misma puntuación al ítem y, en consecuencia, determinaron el mismo grado de presencia en el mensaje analizado). Aplicando la fórmula del coeficiente de fiabilidad de Holsti (1969), el resultado es un coeficiente de 0,926. Dado que un resultado de 1 reflejaría el acuerdo total, el dato obtenido representa un grado muy elevado de acuerdo entre los dos investigadores. Los datos ofrecidos en este artículo sobre el análisis de contenido corresponden al codificador interno del equipo de investigación conformado, quien, al contrario que el segundo codificador, participó activamente en el desarrollo de la metodología.

\section{Resultados}

\section{Datos de las encuestas electorales y de opinión}

Comenzando por el sondeo de Metroscopia previo a las elecciones de diciembre de 2015, éste señalaba tres grandes preocupaciones para los encuestados: el paro, la corrupción y los problemas económicos.

De los tres, fue la corrupción la que arrojó una mayor correlación con la evolución en la intención de voto. Según la encuesta de Metroscopia de diciembre, la mención a la corrupción como principal problema se situaba en el 38,8\%, al mismo tiempo que PP y PSOE se asentaban en cabeza de la encuesta. Pero esta preocupación por la corrupción y el fraude no hizo sino aumentar para las elecciones de junio de 2016, cuando la encuesta de Metroscopia la situó en 44,0\%. Mientras tanto, un 76,4\% señaló entonces la inquietud por el paro ${ }^{1}$.

1 En este último caso hay que tener en cuenta que no sólo se ha incluido a quienes consideraban el paro como principal problema, sino a quienes lo señalaron como un problema con independencia de su magnitud. En consecuencia, podían seleccionar múltiples respuestas, y el acumulado de la pregunta es superior al 100\%. 
Esta preocupación por la economía tiende a registrar diferencias palpables en función de la intención de voto a cada partido. Si se toma como referencia la encuesta de Clima Social de Metroscopia correspondiente a junio de 2016, los votantes de PP y Ciudadanos eran los más convencidos del riesgo para la economía española si no se lograba formar gobierno (esto preocupaba al $86 \%$ y al $81 \%$ de sus votantes, respectivamente). En cambio, la proporción de votantes preocupados por esta cuestión descendía a un 66\% entre los del PSOE, y un 42\% entre los de Unidos Podemos ${ }^{2}$. Al mismo tiempo, el votante del PP era el único que, para entonces, afirmaba notar una mejoría en la economía española: lo hacía el 82\% de quienes pensaban darle su confianza, al mismo tiempo que el $83 \%$ la atribuían a la labor del Gobierno. Esta última cifra descendía hasta el 52\% entre los electores de Ciudadanos. Por su parte, los votantes del PSOE eran los que peor calificaban la situación económica nacional, con un $88 \%$ considerándola muy negativa; y un $74 \%$ también calificaba de esa manera la acción gubernamental al respecto. Entre los de Unidos Podemos, el 94\% calificaba la situación económica de España como "mala"; y el 80\% rechazó cualquier relación entre la actuación del Gobierno y una mejora.

En cuanto a las valoraciones de los cuatro líderes políticos, en diciembre de 2015 sólo Albert Rivera recibía el visto bueno de los encuestados por Metroscopia: Su saldo entre los que aprobaban y desaprobaban su actuación política era el único positivo (+11 puntos), frente a los saldos negativos de Pedro Sánchez (-20 puntos), Pablo Iglesias (-24) y Mariano Rajoy (33). Sólo los respectivos votantes de cada partido otorgaban generosos saldos positivos a sus candidatos. Paralelamente, el 20\% de los encuestados prefería que ganase el PP las elecciones de diciembre de 2015, este dato era del 19\%, el 17\% y el 16\% para PSOE, Podemos y Ciudadanos, respectivamente. Sin embargo, para junio de 2016 Rivera ( -7 puntos) ya se unía a los suspensos en actuación política, con notables bajadas de todos los candidatos en esta pregunta. Ese mismo mes, un $46 \%$ de los encuestados ya se mostraba convencido de que Rajoy continuaría siendo Presidente del Gobierno; sólo un 27\% consideraba que lo sería Sánchez, situado en segundo lugar en esta pregunta.

2 Para valorar en su contexto la evolución de las cifras de Podemos entre las encuestas de 2015 y las de 2016 se debe tener en cuenta que, en abril de este último año, el partido anunció que concurriría bajo la coalición Unidos Podemos, la cual incluía a la formación minoritaria Izquierda Unida (IU). 
Por último, ¿qué papel otorgaron las encuestas a los debates electorales? El Barómetro Postelectoral del CIS de julio de 2016 refleja cómo un 26,3\% de los entrevistados vio el debate entre los cuatro candidatos al completo, junto a un 27,6\% que llegó a ver algún fragmento. Estos datos suponen un ligero descenso respecto a lo registrado en el Postelectoral de las generales de 2015, cuando un 30\% vio entero el cara a cara entre Rajoy y Sánchez, y un 26,5\% vio parte. En aquella ocasión, el CIS reflejó un empate técnico (el 26,1\% afirmó que había ganado Rajoy, frente al 26,9\% que consideró que fue más convincente Sánchez); pero la principal respuesta, escogida espontáneamente por el 37,1\% de los entrevistados, fue "ninguno de los dos". Sin embargo, el dato más llamativo del CIS sobre los debates de aquella campaña electoral es la clara victoria de Pablo Iglesias en el debate entre representantes de los cuatro partidos, pero sin la presencia de Mariano Rajoy: un $31,3 \%$ se decanta por Iglesias como el vencedor de aquel espacio, seguido por Soraya Sáenz de Santamaría (18,3\%). Por su parte, para el debate a cuatro de junio de 2016, un 21,1\% de los encuestados declaró que Mariano Rajoy fue el más convincente, sensiblemente por delante de Iglesias (14,3\%), Sánchez (10,3\%) y Rivera (9,9\%). No obstante, la opción espontánea de que ninguno hubiera ganado volvió a ser la más escogida, tal y como hizo el $32,8 \%$; en cualquier caso, no dejan de ser más de cuatro puntos porcentuales menos que en el cara a cara de seis meses antes.

\section{Resultados de los grupos de discusión}

Tal y como anticipaban las encuestas del CIS cuando se imponía la opción de que ningún candidato había ganado los debates, el consenso alcanzado en ambos grupos de discusión reflejó un desencanto y una falta generalizada de confianza en los políticos por parte del público joven, que se traduce en falta de credibilidad percibida. De hecho, se tuvo que abrir el código "Decepción con la política”, el cual resultó ser el más nutrido, con 37 citas. Ese cansancio es especialmente pronunciado con los dos grandes partidos tradicionales (PP y PSOE), y los actuantes declararon que lo fue también cuando se repitieron las elecciones el 26-J. Las siguientes citas extraídas de las transcripciones reflejan ese sentir generalizado y las conexiones comentadas:

\footnotetext{
"A mí sí me gusta bastante la política, pero llegó un momento en que desconecté, porque estaba cansado de lo que me estaban contando, porque me sonaba a lo mismo”.

“Que Pedro Sánchez y Mariano Rajoy me parecen ya muy cansinos. Muy cansinos”.
} 
Los actuantes aportaron comentarios muy diversos acerca del impacto que los debates electorales habrían tenido en su decisión de voto. Sin embargo, hubo consenso en ambos grupos a la hora de reconocer su interés por los debates electorales, recordando especialmente cómo recibieron el debate a cuatro de junio de 2016 con expectación, al ser la primera vez que el tablero de cuatro partidos se veía las caras en este formato. El código "Nuevos partidos" 3 acumuló 12 citas, las cuales compartió en más de la mitad de los casos con la categoría "Influencia de debates y campañas". Se reitera además la idea de que los debates sirven para ver a los candidatos en un entorno más espontáneo (incluso por actuantes que negaron verse influidos por ellos), tal y como plasmó una de las mujeres jóvenes que participaron con muchos apoyos y ningún disenso:

"Cómo se comportan, si empatizas con ellos, si no empatizas, si te despiertan confianza, si no... Más que por lo que van diciendo o lo que están proponiendo en su programa”.

A esta utilidad (que, como recogimos en el marco teórico, ya ha sido detectada en estudios anteriores), se añade la de descartar candidatos, muy bien acogida en el grupo en el que se propuso. Así la resume un actuante de 28 años:

"No sabía si votar a éste, pero acaba de soltar tal tontería que me reafirmo en que no".

Respecto a la credibilidad atribuida, la principal conclusión exploratoria arroja cómo los jóvenes perciben una falta de eficacia social generalizada en los líderes políticos. Este hallazgo contrasta con la dedicación casi total de los candidatos a trabajar este subfactor en Twitter. Bajo la categoría "Falta de credibilidad de la fuente" se registraron un total de 149 citas, de las cuales 28 se codificaron como "Falta de confianza". En consecuencia, todos los actuantes coincidieron en hacer comentarios con los que criticaban que los candidatos miraran más por sus propios intereses que por los de sus votantes:

\footnotetext{
"Sin ir más lejos, ¿de qué ha hablado el señor Sánchez aquí? Ha hablado de que salgan todos a votar para corregir su problema, que es el de la abstención. ¿De qué ha hablado Rajoy ahí? Pues de que gane la lista más votada. ¿Por qué? Pues porque a él personalmente le conviene. Bueno, a él, a su partido le pudiera convenir”.
}

3 En este código no se incluyeron las referencias explícitas a los candidatos Pablo Iglesias ni Albert Rivera. 
"Yo veo un debate político, y no espero que lo que me estén contando lo vayan a hacer, porque doy por hecho que hay una hipocresía implícita en la política, que me van a contar, me van a vender la moto para que les vote, y que luego nada de eso se va a cumplir”.

Curiosamente, tras la proyección del fragmento de debate de junio de 2016, Mariano Rajoy se reveló como un candidato atractivo para los jóvenes participantes, porque lo perciben como una persona natural, sincera. Diez de las 75 citas bajo el código "Mariano Rajoy" fueron igualmente codificadas con la etiqueta "Atractivo". Les parece además un candidato con conocimiento experto, tanto por experiencia de gestión como por formación. En este sentido, sus nueve citas bajo el código "Experiencia” superan a las de los demás candidatos juntos. Sus puntos débiles se encuentran en una falta de carisma y de liderazgo, mientras que las opiniones estuvieron divididas respecto a su fiabilidad ética.

Por el contrario, Pedro Sánchez generaba desconfianza por una comunicación verbal y no verbal excesivamente artificial. Sánchez es el que más citas registra bajo el código "Falta de confianza" (diez, por encima de las cuatro de Rajoy, las dos de Iglesias y la única cita de Rivera). Se le atribuyeron cualidades negativas como la altivez, el narcisismo y un exceso de ambición, todo lo cual desembocaba en una menor atribución de competencia para gobernar. Sin embargo, aunque los participantes también detectaban el esfuerzo consciente de Pablo Iglesias por resultar creíble, no dejaron por ello de atribuirle sinceridad. Ahora bien, tendieron a reconocer que ha ido perdiendo esa credibilidad con el paso del tiempo, y surgieron opiniones diversas acerca de una posible falta de conocimiento experto para la gestión, con las que no se llegó a alcanzar un consenso. Por último, Albert Rivera recibió críticas tanto por una artificialidad y altivez semejantes a las de Sánchez, como por su escasa experiencia de gestión (y, por lo tanto, sus carencias en el subfactor de la competencia o conocimiento experto). De nuevo, no se alcanzó un consenso acerca de la credibilidad que en conjunto transmitía, registrándose opiniones dispares.

\section{Análisis de contenido en Twitter}

El dinamismo o eficacia social emerge como el subfactor de credibilidad del que más se sirven los candidatos en Twitter, relegando a la fiabilidad ética y el conocimiento experto a papeles secundarios. La formulación de propuestas y la difusión de las actividades del candidato coparon las cuentas de Twitter de todos ellos, dando lugar al predominio de esa categoría de los análisis. Se observa cómo este resultado tan abrumadoramente favorable a la presencia de la eficacia social se explica porque los candidatos tienden a emplear sus 
perfiles para lanzar extensas series de tuits con motivo de cada acto de campaña o de cada intervención en un medio de comunicación.

Sin embargo, aunque todos los candidatos tengan en común el empleo de sus cuentas en Twitter para tratar de mostrarse como dinámicos o eficaces socialmente, se pueden reseñar a su vez una serie de constantes específicas de cada uno de los líderes políticos.

\section{Rajoy, el líder del conocimiento experto}

Si los actuantes en los grupos de discusión reconocían la experiencia de Mariano Rajoy como su gran punto fuerte para resultar creíble, lo cierto es que en ambas elecciones es el candidato que más recurre al factor de competencia o conocimiento experto en Twitter. Resulta evidente cómo saca partido de su condición de presidente en funciones para realizar referencias a los resultados de su Gobierno, frecuentemente en comparación con los del Gobierno socialista que le precedió. En la puntuación del o al 4 aplicada para los ítems del análisis de contenido, los mensajes de Rajoy arrojan medias de entre o,55 y o,62 puntos en conocimiento experto en los periodos analizados, cuando el resto de candidatos en ningún caso registran más de un 0,5 de media.

Esta diferencia en la intensidad de la presencia del subfactor de conocimiento experto puede parecer muy ligera, pero se eleva drásticamente hasta medias de 1,76 puntos sobre 4 en aquellos tuits publicados durante los días previos al cara a cara del 14 de diciembre, que aludieran a debates electorales (Tabla 4); y 1,68 puntos en el caso de los días previos al debate a cuatro del 14 de junio (Tabla 5).

Perspectivas de la Comunicación - Vol. 13 - No 2 - 2020 - pp. 105-151

Universidad de la Frontera - Chile 
Tabla 4. Promedios de puntuación de las variables de credibilidad (del o al 4) en tuits con referencias a debates electorales publicados del 30 de noviembre al 14 de diciembre de 2015 (entre paréntesis, la desviación estándar).

\begin{tabular}{|l|c|c|c|c|}
\hline & $\begin{array}{l}\text { Conocimiento } \\
\text { experto/ } \\
\text { competencia }\end{array}$ & $\begin{array}{l}\text { Fiabilidad } \\
\text { ética }\end{array}$ & $\begin{array}{l}\text { Dinamismo/ } \\
\text { eficacia } \\
\text { social }\end{array}$ & $\begin{array}{l}\text { No tuits } \\
\text { con } \\
\text { mención } \\
\text { a } \\
\text { debates }\end{array}$ \\
\hline $\begin{array}{l}\text { Mariano } \\
\text { Rajoy }\end{array}$ & $\mathbf{1 , 7 6 ( 1 , 6 9 )}$ & o (0) & $3,12(1,65)$ & 33 \\
\hline $\begin{array}{l}\text { Pedro } \\
\text { Sánchez }\end{array}$ & o (0) & $0,95(1,63)$ & $2,67(1,68)$ & 21 \\
\hline $\begin{array}{l}\text { Pablo } \\
\text { Iglesias }\end{array}$ & $0,18(0,57)$ & $1(1,41)$ & $2,55(1,62)$ & 11 \\
\hline $\begin{array}{l}\text { Albert } \\
\text { Rivera }\end{array}$ & 0 & $0,24(0,85)$ & $2,91(1,60)$ & 46 \\
\hline
\end{tabular}

Fuente: Elaboración propia.

Tabla 5. Promedios de puntuación de las variables de credibilidad en tuits con referencias a debates electorales publicados del 30 de mayo al 13 de junio de 2016 (entre paréntesis, la desviación estándar).

\begin{tabular}{|l|l|l|l|l|}
\hline & $\begin{array}{l}\text { Conocimiento } \\
\text { experto/ } \\
\text { competencia }\end{array}$ & $\begin{array}{l}\text { Fiabilidad } \\
\text { ética }\end{array}$ & $\begin{array}{l}\text { Dinamismo/ } \\
\text { eficacia } \\
\text { social }\end{array}$ & $\begin{array}{l}\text { No tuits } \\
\text { con } \\
\text { mención } \\
\text { a } \\
\text { debates }\end{array}$ \\
\hline $\begin{array}{l}\text { Mariano } \\
\text { Rajoy }\end{array}$ & $\mathbf{1 , 6 8}(1,85)$ & $0,36(1,16)$ & $3,34(1,33)$ & 44 \\
\hline $\begin{array}{l}\text { Pedro } \\
\text { Sánchez }\end{array}$ & $1,06(1,62)$ & $0,13(0,52)$ & $3,13(1,64)$ & 15 \\
\hline $\begin{array}{l}\text { Pablo } \\
\text { Iglesias }\end{array}$ & 0 & 0 & $3,14(1,46)$ & 7 \\
\hline $\begin{array}{l}\text { Albert } \\
\text { Rivera }\end{array}$ & $0,23(0,90)$ & $1(1,69)$ & $3,05(1,45)$ & 39 \\
\hline
\end{tabular}


Fuente: Elaboración propia.

Sólo Pedro Sánchez, entre el 30 de mayo y el 13 de junio de 2016 (1,06 puntos), se acerca a los registros de Rajoy en mensajes que combinaran referencias a competencia o conocimiento experto con alusiones a los debates.

\section{Iglesias, predilección por mostrarse atractivo}

A pesar del papel del dinamismo o eficacia social como elemento vertebrador de la gran mayoría de mensajes publicados por los candidatos en sus cuentas de Twitter, Pablo Iglesias lo modera ligeramente más que sus adversarios. Al mismo tiempo, es el candidato que puntúa más alto en el recurso al atractivo como factor de imagen. Como muestra, la presencia media del ítem 'Atractivo' en sus mensajes del 14 al 20 de junio de 2016 es casi un punto superior a la de sus adversarios en el mismo periodo (Tabla 6). Iglesias no sólo publica imágenes suyas o de actos llenos de gente, sino que publica con más frecuencia mensajes o respuestas a otros usuarios en los cuales prima la similitud de gustos, la similitud sociodemográfica o la simpatía, sobre los contenidos de carácter más puramente político.

Tabla 6. Comparativa de la presencia del subfactor de eficacia social y el factor del atractivo (puntuaciones promedio del o al 4), en tuits del 14 al 20 de junio de 2016 (entre paréntesis, la desviación estándar).

Fuente: Elaboración propia.

\begin{tabular}{|l|l|l|l|}
\hline & $\begin{array}{l}\text { Dinamismo/ } \\
\text { eficacia } \\
\text { social }\end{array}$ & $\begin{array}{l}\text { No de } \\
\text { mensajes } \\
\text { analizados }\end{array}$ & Atractivo \\
\hline $\begin{array}{l}\text { Mariano } \\
\text { Rajoy }\end{array}$ & $3,06(1,43)$ & 367 & $2,28(1,60)$ \\
\hline $\begin{array}{l}\text { Pedro } \\
\text { Sánchez }\end{array}$ & $3,13(1,44)$ & 300 & $2,23(1,64)$ \\
\hline $\begin{array}{l}\text { Pablo } \\
\text { Iglesias }\end{array}$ & $\mathbf{2 , 3 3 ( 1 , 8 6 )}$ & $\mathbf{5 0}$ & $\mathbf{3 , 1 9}(\mathbf{1 , 3 8})$ \\
\hline $\begin{array}{l}\text { Albert } \\
\text { Rivera }\end{array}$ & $\mathbf{2 , 8 8 ( 1 , 4 8 )}$ & 345 & $2,38(1,43)$ \\
\hline
\end{tabular}


No obstante, también conviene tener en cuenta que Iglesias es el candidato con la muestra más pequeña. Así, entre el 30 de noviembre y el 20 de diciembre de 2015, se han registrado 186 tuits de Iglesias frente a los 672 de Rajoy o los 433 de Sánchez.

\section{La fiabilidad ética, un referente ocasional y desigual entre candidatos}

Durante la campaña del 2015, quienes más recurrieron al subfactor de la fiabilidad ética fueron Iglesias y Sánchez. De hecho, Pedro Sánchez lo empleó con más intensidad en los mensajes que hacían referencia a debates electorales. Esta tendencia se agudiza entre el 15 y el 20 de diciembre de 2015, precisamente en los días posteriores a su cara a cara con Mariano Rajoy; en estos tuits se vuelve tan pronunciada, que las medias registradas para el ítem 'Fiabilidad ética' se acercan incluso a las de eficacia social (Tabla 7).

Tabla 7. Promedios de puntuación de los factores de credibilidad (del o al 4) en tuits con referencia a los debates electorales publicados del 15 al 20 de diciembre de 2015 (entre paréntesis, la desviación estándar).

\begin{tabular}{|l|l|l|l|l|}
\hline & $\begin{array}{l}\text { Conocimiento } \\
\text { experto/ } \\
\text { competencia }\end{array}$ & $\begin{array}{l}\text { Fiabilidad } \\
\text { ética }\end{array}$ & $\begin{array}{l}\text { Dinamismo/ } \\
\text { eficacia } \\
\text { social }\end{array}$ & $\begin{array}{l}\text { tuits } \\
\text { con } \\
\text { mención } \\
\text { a } \\
\text { debates }\end{array}$ \\
\hline $\begin{array}{l}\text { Mariano } \\
\text { Rajoy }\end{array}$ & $0,6(1,34)$ & 0 & $3,6(0,89)$ & 5 \\
\hline $\begin{array}{l}\text { Pedro } \\
\text { Sánchez }\end{array}$ & o (0) & $2,23(1,88)$ & $3(1,22)$ & 13 \\
\hline $\begin{array}{l}\text { Pablo } \\
\text { Iglesias }\end{array}$ & 1 & 0 & 4 & 1 \\
\hline $\begin{array}{l}\text { Albert } \\
\text { Rivera }\end{array}$ & $0,32(1,04)$ & o (o) & $3,5(0,91)$ & 22 \\
\hline
\end{tabular}

Fuente: Elaboración propia.

El fenómeno opuesto se observa al analizar los mensajes de Rivera: Cuando los tuits tenían que ver con los debates de la campaña del 20-D, apenas hacía referencia al factor de la fiabilidad ética. En cambio, dicho factor obtiene todo un punto en los mensajes de la campaña del 26-J relacionados con los debates y, durante la campaña para dichas 
elecciones, Albert Rivera pasa a ser el candidato que más alude al subfactor de fiabilidad ética u honestidad. En otras palabras, se observa que la presencia de Rivera en el debate a cuatro de junio de 2016 (frente a su ausencia en el cara a cara de diciembre de 2015) le sirvió para incidir más en su propia fiabilidad ética y en las carencias que atribuía a Rajoy en este campo.

Por su parte, aunque se aprecia cómo Rajoy y el Partido Popular hicieron algunas menciones a medidas para acabar con la corrupción, el proceso de codificación las desenmascara como anecdóticas: Entre 0,1 y o,2 puntos sobre 4 en cualquiera de los periodos analizados. Como hemos señalado anteriormente, Rajoy se decantó con más frecuencia por las referencias a su gestión como prueba de su competencia.

\section{Temáticas y relación con los factores de credibilidad}

Aunque el discurso de Rajoy en redes es muy completo a la hora de tocar las cuatro áreas temáticas definidas, se aprecia en todos los periodos una jerarquía clara: En primer lugar habla, ante todo, de economía y empleo, seguida de las políticas sociales, la política exterior y, en última posición, las cuestiones sobre regeneración democrática. Llama la atención cómo frecuentemente pone en relación la economía y el empleo con ese mencionado conocimiento experto o competencia: Lo hace en 284 de sus 874 tuits durante la campaña de diciembre de 2015, es decir, aproximadamente en uno de cada cuatro mensajes; y en 262 de los 774 mensajes (el 35,14\%) durante la de junio de 2016. Además, de acuerdo a la escala del o al 4 para la medición de los ítems, la intensidad media de esta presencia se sitúa en torno al 1 o por encima en todos los periodos delimitados, un dato claramente superior al del resto de categorías del bloque de temas.

Por lo que respecta a Albert Rivera, durante la campaña del 20-D no hay diferencias pronunciada entre la frecuencia con la que trae a colación los temas de economía y empleo, políticas sociales y regeneración democrática. Sin embargo, destaca por ser un candidato que alude a ésta última (reforma de las administraciones, defensa de la Constitución, etc.), más habitualmente que sus rivales, registrándose en 78 de los 545 tuits (14,31\%) de diciembre de 2015, y en 177 de los 774 mensajes correspondientes a la campaña de junio de 2016 (el 22,87\%). No obstante, para la campaña del 26-J incrementó la atención que dedicaba en la red social Twitter a la economía. Ahora bien, Rivera apenas se sirvió del subfactor del conocimiento experto, basando en las argumentaciones y el dinamismo casi toda su credibilidad.

Perspectivas de la Comunicación - Vol. 13 - No 2 - 2020 - pp. 105-151

Universidad de la Frontera - Chile 
Por su parte, Pedro Sánchez y Pablo Iglesias se distancian de sus rivales Rajoy y Rivera, en cuanto a que se distinguen por ser los candidatos que priorizan las políticas sociales por delante de los demás bloques. La evolución de Iglesias de la primera campaña a la segunda es palpable, pues la regeneración democrática se convierte en su tema predilecto durante diciembre de 2015 (figura en 56 de los 257 mensajes lanzados durante ese periodo, uno de cada cinco tuits publicados), para centrarse definitivamente en las políticas sociales de cara a las elecciones del 26-J (la categoría se codifica en 47 de los 195 tuits, uno de cada cuatro).

\section{Ataques y defensas}

En lo que respecta a estos ítems, los candidatos dedican poco tiempo a mostrarse a la defensiva. El número de tuits que tuvieron que ser codificados en mayor o menor grado como ataques supera cómodamente a los tuits de defensa en todos los casos, ya sea antes o después de cada debate tomado como referencia; ya sea en la campaña de diciembre de 2015 o en la de junio de 2016.

Merece la pena destacar la llamativa evolución que se observa en Pedro Sánchez antes y después del cara a cara del 14 de diciembre. Las estadísticas del análisis de contenido de su cuenta en Twitter arrojan una campaña en dos partes marcadamente separadas por el debate electoral.

Así, en las dos semanas que abarcan desde el 30 de noviembre hasta el 14 de diciembre de 2015, Sánchez publica un total de 101 tuits codificables como ataques a otros candidatos u organizaciones, al mismo tiempo que se defiende (o defiende a su partido) en siete ocasiones. Pero súbitamente, en los seis últimos días (del 15 al 20 de diciembre), los posteriores al debate con Mariano Rajoy, Sánchez emplea casi el mismo número de mensajes para atacar o para defenderse (114 tuits en total) que se acerca al registrado en total durante las dos semanas anteriores (Tabla 8).

Cabe recordar que Sánchez fue fuertemente criticado por unas formas que se consideraron muy agresivas frente a Rajoy en el debate a dos, por lo que se aprecia cómo empleó una gran parte de sus tuits (surgidos a su vez de su participación en actos y entrevistas) a reiterar las críticas vertidas en dicho espacio y a defender la actitud que él mismo adoptó esa noche. 
Cabe recordar en este punto que Sánchez apenas ganó por unas décimas a Rajoy en el cara a cara, de acuerdo con los resultados postelectorales del CIS; y que los participantes en los focus groups coincidieron en reprocharle altivez y artificialidad en su comportamiento ante la cámara. Son indicios de que la combinación del subfactor de fiabilidad ética con el aumento de sus mensajes defensivos no resultaron efectivos en términos de credibilidad.

Otra evolución para subrayar es la de Pablo Iglesias, antes y después del debate del 13 de junio de 2016 (Tabla 8). En los últimos siete días analizados, Iglesias lanza seis ataques y se defiende en otras seis ocasiones; reduce de esta manera drásticamente la proporción de ataques que había vertido hasta que los candidatos llegaron al debate a cuatro. Se observa, por lo tanto, un ligero cambio de tono o un perfil más bajo con posterioridad a esa cita clave. Dicha evolución tampoco parece funcionar entre los actuantes de los grupos de discusión, quienes coinciden en señalar una progresiva reducción de la credibilidad de Iglesias a lo largo del tiempo.

Tabla 8. Número de tuits en los que los candidatos lanzan un ataque o se defienden

\begin{tabular}{|l|l|l|l|l|}
\hline & \multicolumn{3}{|l|}{$\begin{array}{l}\text { Sánchez (del 30 de noviembre } \\
\text { al 20 de diciembre de 2015) }\end{array}$} & \multicolumn{2}{l|}{$\begin{array}{l}\text { Iglesias (del 14 al 20 de } \\
\text { junio de 2016) }\end{array}$} \\
\hline & $\begin{array}{l}\text { Antes del } \\
\text { debate (15 } \\
\text { días) }\end{array}$ & $\begin{array}{l}\text { Después del } \\
\text { debate } \\
\text { días) }\end{array}$ & $\begin{array}{l}\text { Antes del } \\
\text { debate (15 } \\
\text { días) }\end{array}$ & $\begin{array}{l}\text { Después } \\
\text { del } \\
\text { debate (7 } \\
\text { días) }\end{array}$ \\
\hline Ataque & 101 & 87 & 22 & 6 \\
\hline Defensa & 7 & 27 & 9 & 6 \\
\hline
\end{tabular}

Fuente: Elaboración propia.

\section{Conclusiones}

La gran mayoría de registros recogidos mediante los análisis de contenido se mantuvieron constantes antes y después de los debates. Ahora bien, al reseñar aquellas variables que sí evolucionan en determinados candidatos, se constatan algunos impactos puntuales de los debates electorales sobre el desarrollo posterior de la actividad de sus cuentas en Twitter. El caso más notable es el de Pedro Sánchez tras el debate cara a cara con Mariano Rajoy, incrementando a partir de ese momento sus ataques y sus alusiones al subfactor de fiabilidad ética. Mientras que, a juzgar por los resultados de los focus groups, estas evoluciones de los factores de credibilidad a lo largo del tiempo no han resultado positivas ni para Sánchez ni 
para Iglesias, los esfuerzos de Mariano Rajoy sí se revelan adecuadamente sincronizados. En su perfil de Twitter, Rajoy trabajó constantemente en un marco de percepción positivo para que se le atribuyera competencia o conocimiento experto: Existe un paralelismo entre su actividad en Twitter, el reconocimiento inequívoco de tales capacidades en los grupos de discusión, y la estimación de los encuestados por Metroscopia sobre su capacidad para la gestión económica.

Ante todo, los candidatos emplearon el potencial de Twitter para tratar de mostrarse dinámicos y activos. Se trata de un aspecto que importa más que ningún otro al público joven, tal y como expresaron en los focus groups llevados a cabo. Es más, vinculan claramente los debates electorales a la detección de cómo se comportan los candidatos en un entorno menos medido, lo que coincide plenamente con la aseveración de Coleman y Moss (2016: 11) sobre la utilidad de los debates para descubrir la verdadera cara de los políticos En consecuencia, el recurso a la eficacia social, a la que tantos mensajes dedicaron los contendientes, contrasta con la percepción generalizada de ineficacia, tal y como se desprende de los grupos de discusión.

De forma similar, la gran preocupación por la corrupción y el fraude que se recogía en los sondeos de opinión (y que también emerge cuando los jóvenes están de acuerdo en afirmar que los políticos sólo miran por sus intereses), tampoco se correlaciona plenamente con la atención moderada que dedican los candidatos a la fiabilidad ética en sus mensajes; salvo contadas excepciones (Rivera en junio de 2016, Iglesias en diciembre de 2015, Sánchez tras el enfrentamiento con Rajoy) tampoco lo hace con el papel que le otorgan a la regeneración democrática. Es más, a ojos de los encuestados, ningún candidato era lo suficientemente creíble para afrontar los problemas del país, puesto que todos acabaron suspendiendo la valoración de sus actuaciones; y ello a pesar del papel preponderante de la economía, el empleo y las políticas sociales en sus discursos a través de Twitter. Si tomamos en consideración que Chaves-Montero, Gadea-Aiello y Aguaded-Gómez (2017: 79) ya concluyeron que la falta de un tráfico de calidad y una adecuada segmentación de los mensajes en redes sociales eran problemas especialmente acuciantes para PP y PSOE, una mayor atención a estos aspectos contribuiría a encauzar las atribuciones de eficacia social entre el público joven.

En suma, de acuerdo con esa preferencia por trabajar la eficacia social, común a todos los candidatos, las diferencias en cuanto al trabajo en la credibilidad no fueron notables en 
Twitter, más allá del mencionado giro de Pedro Sánchez hacia la fiabilidad ética; la casi total omisión de referencias a ese mismo subfactor por parte de Mariano Rajoy, y el mayor esfuerzo por el factor del atractivo que demuestra la cuenta de Pablo Iglesias; un Pablo Iglesias en quien, al menos, los jóvenes reconocen sinceridad, al mismo tiempo que, según su percepción, su credibilidad ha menguado progresivamente.

La verdadera disonancia llega cuando un público joven que declara interesarse por los debates electorales reduce toda la influencia que éstos pueden tener sobre su decisión de voto al descarte de los candidatos que no les resulten creíbles. Pero probablemente la conclusión más sorprendente de esta investigación resida en los parámetros por los que los jóvenes atribuyen credibilidad a las fuentes (esto es, los candidatos). De nuevo, Rajoy destaca por encima de sus adversarios; y no sólo lo hace por su conocimiento experto, sino también por su mayor naturalidad percibida ante la cámara. La atribución de honestidad que el presidente en funciones descuidaba en Twitter, la recuperaba en los debates, al no destilar la artificialidad que los actuantes percibían en Sánchez y Rivera. 


\section{Referencias bibliográficas}

ARCEO, J. L. (Dir.) (1993): Campañas Electorales y Publicidad Política en España (19761991). Barcelona:ESRP-PPU.

BENOIT, W. L. y HANSEN, G. J. (2001): Presidential debate questions and the public agenda. Communication Quarterly, 49(2), pp. 130-146. https://doi.org/10.1080/01463370109385621.

BERMINGHAM, A, y SMEATON, A. F. (2011): On using Twitter to monitor political sentiment and predict election results, en Proceedings of the Workshop on Sentiment Analysis where AI meets Psychology (SAAIP), 5th International Joint Conference on Natural Language Processing. Chiang Mai, Tailandia, 13 de noviembre de 201. Asian Federation of Natural Language Processing, pp. 2-10. Disponible en: https://www.aclweb.org/anthology/W11-3702.pdf.

BERROCAL, S. (2004): Una aproximación a la nueva retórica del líder político televisivo: acciones, cualidades y discurso. Doxa Comunicación: Revista Interdisciplinar de Estudios de Comunicación y Ciencias Sociales, (2), pp. 53-67. Disponible en: https://repositorioinstitucional.ceu.es/bitstream/10637/5989/1/NoII_pp53_67.pdf.

BOEHM, L. E. (1994): The validity effect: A search for mediating variables. Personality and Social Psychology Bulletin, 20(3), pp. 285-293.

CASTELLS, M. (Ed.) (2006): La Sociedad Red: Una visión global. Madrid: Alianza editorial (Alianza Ensayo).

CAMPOS-DOMÍNGUEZ, E. (2017): Twitter y la comunicación política. El Profesional de la Información, 26(5), pp. 785-793. https://doi.org/10.3145/epi.2017.sep.01.

CASERO-RIPOLlÉS, A., MIQUEL-SEGARRA, S. y ALONSO-MUÑOZ, L. (2016): The dialogic potential of Twitter in electoral campaign. The case of PSOE and Podemos in Spain, en 2016 11th Iberian Conference on Information Systems and Technologies (CISTI), Las Palmas, España, 15-18 de junio de 2016. Pp. 1-6. 
CHADWICK, A. (2013): The hybrid media system: Politics and Power. Nueva York: Oxford University Press.

CHAIKEN, S. y MAHESWARAN, D. (1994): Heuristic processing can bias systematic processing: Effects of source credibility, argument ambiguity, and task importance on attitude judgment. Journal of Personality and Social Psychology, 66(3), pp. 460-473.

CHARMAZ, K. C. (2006): Constructing Grounded Theory: A Practical Guide Through Qualitative Analysis. California: Sage.

CHAVES-MONTERO, A. y GADEA-AIELLO, W.F. (2017): Uso, efectividad y alcance de la comunicación política en las redes sociales, en CHAVES-MONTERO, A. (Ed.), Comunicación política y redes sociales. pp. 13-32. Sevilla: Ediciones Egregius.

CHAVES-MONTERO, A., GADEA-AIELLO, W. F. y AGUADED-GÓMEZ, J. I. (2015): La comunicación política en las redes sociales durante la campaña electoral de 2015 en España: Uso, efectividad y alcance. Perspectivas de la Comunicación, 1o(1), pp. 55-83. Disponible en: https://doi.org/10.13140/RG.2.2.30012.44165.

CHIHU, A. (2008): El framing de los debates presidenciales en México (1994-2006). Ciudad de México: UAM-Porrúa.

COLEMAN, S. y MOSS, G. (2016): Rethinking election debates: What citizens are entitled to expect. The International Journal of Press/Politics, 21(1), pp. 3-24. Disponible en: https://doi.org/10.1177/1940161215609732.

DADER, J. L. y CAMPOS-DOMÍNGUEZ, E. (2017): La búsqueda digital del voto: Cibercampañas electorales en España. 2015-16. Valencia: Tirant lo Blanch (Comunicación Política y Estrategias de Campaña, 4).

DALTON, R. J. (2014): Interpreting partisan dealignment in Germany. German Politics, 23(1-2), pp. 134-144. 
DALTON, R. J., MCALliSTER, I. y WATTENBERG, M. P. (2000): The consequences of partisan dealignment, en Dalton, R. J. y Wattenberg, M. P. (Eds.), Parties without partisans, pp. 37-63. Oxford: Oxford University Press.

DEL-REY-MORATÓ, J. (2011): La comunicación política en la sociedad del marketing y de internet. Encuadres, relatos y juegos de lenguaje. Revista de comunicación, 1O, pp. 102-128. Disponible en: https://revistadecomunicacion.com/pdf/2011/Art102-128.pdf.

DELTELL, L. (2014): Audiencia social versus audiencia creativa: caso de estudio Twitter. Estudios sobre el Mensaje Periodístico, 20(1), pp. 33-47. Disponible en: https://doi.org/10.5209/rev_ESMP.2014.v20.n1.45217.

DIAKOPOULOS, N. A. y SHAMMA, D. A. (2010): Characterizing debate performance via aggregated Twitter sentiment, en $\mathrm{CHI} 2 \mathrm{O1O}$ - The 28th Annual CHI Conference on Human Factors in Computing Systems, Conference Proceedings (Vol. 2). Atlanta, EE.UU., 10-15 de abril de 2010. Pp. 1195-1198. Disponible en: https://doi.org/10.1145/1753326.1753504.

DRUCKMAN, J. N. (2001): On the limits of framing effects: who can frame? The Journal of Politics, 63(4), pp. 1041-1066.

EFFING, R., VAN HILLEGERSBERG, J. y HUIBERS, T. W. C. (2011): Social media and political participation: Are Facebook, Twitter and YouTube democratizing our political systems?, en Electronic Participation. Third IFIP WG 8.5 International Conference, ePart 2011(Lecture Notes in Computer Science, Vol. 6847). Londres, Reino Unido, 29 de agosto 1 de septiembre de 2011. Springer, pp. 25-35.

ENTMAN, R. M. (1993): Framing: Toward clarification of a fractured paradigm. Journal of Communication, 43(4), pp. 51-58.

FESTINGER, L. (1957): A theory of cognitive dissonance. Stanford (EE.UU.): Stanford University Press.

GAITÁN, J. A. y PIÑUEL, J. L. (2010): Técnicas de investigación en Comunicación Social: Elaboración y registro de datos. Madrid: Síntesis. 
GARCÍA-ORTEGA, C. y ZUGASTI-AZAGRA, R. (2014): La campaña virtual en Twitter: análisis de las cuentas de Rajoy y de Rubalcaba en las elecciones generales de 2011. Historia y Comunicación Social, 19(número especial febrero), Disponible en: https://doi.org/10.5209/rev_HICS.2014.v19.45029.

GEER, J. G. (1988): The effects of presidential debates on the electorate's preferences for candidates. American Politics Research, 16(4), pp. 486-501.

GELADO M. R. y BONETE-VIZCAÍNO, F. (2018): Politics 2.o? Spanish candidates on Twitter during the European Elections 2014, en FRAME, A. y BRACHOTTE, G.: L'usage de Twitter par les candidats \#Eurodéputés @Europarl_FR @Europarl_EN: Perspectives internationales lors des élections au Parlement européen en mai 2014. pp. 261-282. Caen (Francia): Editions EMS.

GELMAN. A. y KING, G. (1993): Why are American presidential election campaign polls so variable when votes are so predictable?. British Journal of Political Science, 23(4), pp. 409-451.

GOFFMAN, E. (1974): Frame analysis: An essay on the organization of experience. Cambridge (EE.UU.): Harvard University Press.

GRABER, D. A. (Ed.) (1980): Media power in politics. Washington, D.C.: CQ Press.

HARRINGTON, S., HIGHFIELD, T. y BRUNS, A. (2013): More than a backchannel: Twitter and television. Participations: Journal of Audience \& Reception Studies, 10(1), pp. 405-409. Disponible en: http://snurb.info/files/2014/More\%20than\%20a\%2oBackchannel.pdf.

HOLBROOK, T. M. y MCCLURG, S. D. (2005): The mobilization of core supporters: Campaigns, turnout, and electoral composition in United States presidential elections. American Journal of Political Science, 49(4), pp. 689-703.

HOLSTI, O. R. (1969): Content analysis for the Social Sciences and Humanities. Reading (EE.UU.): Addison-Wesley. 
HOVLAND, C. I. y WEISS, W. (1951): The influence of source credibility on communication effectiveness. Public Opinion Quarterly. 15 (4), pp. 635-650.

HOVLAND, C. I., JANIS, I. L. y KELLEY, H. H. (1953): Communication and Persuasion. New Haven (EE.UU.): Yale University Press.

IYENGAR, S. y MCGUIRE, W. J. (Eds.) (1995): Explorations in Political Psychology. Durham (EE.UU.): Duke University Press.

JENSEN, M. J. y ANSTEAD, N. (2013): Psephological investigations: Tweets, votes, and unknown unknowns in the republican nomination process. Policy and Internet, 5(2), pp. 161-182.

KAID, L. (Ed.) (2004): Handbook of Political Communication Research. Mahwah (EE.UU.): Lawrence Erlbaum Associates.

KANTAR MEDIA (2016): Kantar Twitter TV Ratings: A year in the life of TV and Twitter in Spain. España: Kantar Media

KARLSEN, R. y ENJOLRAS, B. (2016): Styles of Social Media Campaigning and Influence in a Hybrid Political Communication System: Linking Candidate Survey Data with Twitter Data. The International Journal of Press/Politics, 21(3), pp. 338-357.

KNOBLOCH-WESTERWICK, S. y MENA, J. (2009): Looking the other way: Selective exposure to attitude-consistent and counterattitudinal political information. Communication Research, 36(3), pp. 426-448.

LAKOFF, G. (2007): No pienses en un elefante. Madrid: Editorial Complutense. (2013): Puntos de reflexión. Manual del progresista: cómo transmitir los valores [y] la visión progresista estadounidenses. Ed. rev., Barcelona: Península.

LAKOFF, G., y WEHLING, E. (2016): Your Brain's Politics: How the Science of Mind Explains the Political Divide. Luton (Reino Unido): Andrews UK (Societas Series). 
LASSEN, D. S. y BROWN, A. R. (2011): Twitter: The electoral connection? Social Science Computer Review, 29(4), pp. 419-436.

LASSWELL, H. D. (1974): La política como reparto de influencia. Madrid: Aguilar.

LAU, R. R. y SEARS, D. O. (Eds.) (1986): Political Cognition. Hillsdale, Nueva Jersey: Lawrence Erlbaum Associates.

LAWSON, C. (2002): Building the fourth estate: Democratization and the rise of a free press in Mexico. Berkekey, California: University of California press.

LAWSON, C. y MCCANN, J. A. (2005): Television news, Mexico's 20oo elections and media effects in emerging democracies. British Journal of Political Science 35(1), pp. 1-30.

LAWSON, C., CHAPPELL, H., LENZ, G. S., BAKER, A. y MYERS, M. (2010): Looking like a winner: Candidate appearance and electoral success in new democracies. World Politics, 62(4), pp. 561-593.

LIAO, V. y FU, W.T. (2013): Beyond the filter bubble: Interactive effects of perceived threat and topic involvement on selective exposure to information en CHI '13: Proceedings of the SIGCHI Conference on Human Factors in Computing Systems, $31^{\text {st }}$ ACM conference on Computer-Human Interaction. París, Francia, 27 de abril a 2 de mayo de 2013, pp. 23592368. Disponible en: https://doi.org/10.1145/2470654.2481326.

LÓPEZ-GARCÍA, G. (2016): 'Nuevos' y 'viejos' liderazgos: la campaña de las elecciones generales españolas de 2015 en Twitter. Comunicación y sociedad, 29(3), pp. 149-167. Disponible en: https://doi.org/10.15581/003.29.3.149-168.

LÓPEZ-GARCÍA, G.; LLORCA-ABAD, G.; VALERA-ORDAZ, L. y PERIS-BLANES, À. (2018): Los debates electorales, cel último reducto frente la mediatización? Un estudio de caso de las elecciones generales españolas de 2015. Palabra Clave, 21(3), pp. 772-797.

LÓPEZ-MERI, A., MARCOS-GARCÍA, S. y CASERO-RIPOLLÉS, A. (2017): ¿Qué hacen los políticos en Twitter? Funciones y estrategias comunicativas en la campaña electoral 
española de 2016. El Profesional de la Información, 26(5), pp. 795-804. Disponible en: https://doi.org/10.3145/epi.2017.sep.o2.

LORENTE-CANO, M. (2011): Social TV en España: concepto, desarrollo e implicaciones. Cuadernos de Gestión de Información, 1, pp. 55-64. Disponible en: https://revistas.um.es/gesinfo/article/view/207531.

MAGALHAES, P. (2007): Voting and intermediation: Informational biases and electoral choices in comparative perspective, en GUNTHER, R., MONTERO, J. R. y PUHLE, H.J. (Eds.), Democracy, Intermediation, and Voting on Four Continents. pp. 208-254. Oxford: Oxford University Press.

MAZAIRA-CASTRO, A., RÚAS-ARAÚJO, J. y PUENTES-RIVERA, I. (2019): Fact-checking en los debates electorales televisados de las elecciones generales de 2015 y 2016. Revista Latina de Comunicación Social, 74, pp. 748-766. Disponible en: https://doi.org/10.4185/RLCS-2019-1355.

MCCOMBS, M. E. y SHAW, D. L. (1972): The agenda-setting function of mass media. The Public Opinion Quarterly, 36(2), pp. 176-187.

MCGUIRE, W. J. (1969): The nature of attitude and attitude change, en LINDZEY, G. y ARONSON, E.: The Handbook of Social Psychology, V, vol. 3. pp. 136-314. Reading (EE.UU.): Addison-Wesley.

(1972): Attitude change: The Information Processing Paradigm, en McClintock, C.G., Experimental Social Psychology. pp. 108-141, Nueva York: Holt, Rinehart, and Winston. (1985): Attitudes and attitude change, en LINDZEY, G. y ARONSON, E.: The Handbook of Social Psychology, vol. 2. 3era ed., pp. 233-346. Nueva York: Random House.

MCKINNEY, M. S. y WARNER, B. R. (2013): Do presidential debates matter? Examining a decade of campaign debates effects. Argumentation and Advocacy, 49(4), pp. 238-258.

MESSING, S. y WESTWOOD, S. J. (2012): Selective exposure in the age of social media: Endorsements Trump partisan source affiliation when selecting news online. Communication Research, 41(8), pp. 1042-1063. 
METZGER, M. J., FlANAGIN, A. J., EYAL, K., LEMUS, D. R. y MCCANN, R. M. (2003): Credibility for the 21st Century: Integrating perspectives on source, message, and media credibility in the contemporary media environment. Annals of the International Communication Association, 27(1), pp. 293-335. https://doi.org/10.1080/23808985.2003.11679029.

METZGER, M. J. y FLANAGIN, A. J. (2013): Credibility and trust of information in online environments: The use of cognitive heuristics. Journal of Pragmatics, 59(B), pp. 210-220.

MILLER, W. (1991): Media and voters: The audience, content and influence of press and television at the 1987 General Election. Oxford: Clarendon Press.

NEWMAN, B. I. (Ed.) (1999): Handbook of Political Marketing. Thousand Oaks (EE.UU.): Sage.

NORRIS, P., CURTICE, J., SANDERS, D., Scammell, M. y SEMETKO, H. A. (1999): On message: Communicating the campaign. Londres: SAGE.

PAN, Z. y KOSICKI, G. M. (2001): Framing as a strategic action in public deliberation, en REESE, S. D., GANDY JR., O. H. y GRANT, A. E.: Framing Public Life: Perspectives on Media and our Understanding of the Social World. pp. 35-66. Mahwah, (EE.UU.): Lawrence Erlbaum Associates.

PFAU, M. (2002): The subtle nature of presidential debate influence. Journal Argumentation and Advocacy, 38(4), pp. 251-261.

PINKER, S., y LAKOFF, G. (2007): Does language frame spolitics? Public Policy Research, 14(1), pp. 59-71.

QUEVEDO-REDONDO, R., PORTALÉS-OLIVA, M. y BERROCAL-GONZALO, S. (2016): El uso de la imagen en Twitter durante la campaña electoral municipal de 2015 en España. Revista Latina de Comunicación Social, 71(1), pp. 85-107. Disponible en: https://doi.org/10.4185/RLCS-2016-1085. 
RUIZ-DEL-OLMO, F. J. y BUSTOS-DÍAZ, J. (2016): Del tweet a la fotografía, la evolución de la comunicación política en Twitter hacia la imagen. El caso del debate del estado de la nación en España. Revista Latina de Comunicación Social, 71(1), pp. 108-123. Disponible en: https://doi.org/10.4185/RLCS-2016-1086.

SHAW, D. R. (1999): The effect of TV ads and candidate appearances on statewide presidential votes, 1988-96. American Political Science Review, 93(2), pp. 345-361.

SMITH, A. y BOYLES, J. L. (2012): The rise of the 'connected viewer' (PDF). Pew Research Center's Internet \& American Life Project, Washington D.C. Disponible en: https://www.pewresearch.org/internet/2012/07/17/the-rise-of-the-connected-viewer-2/ [Consultado 3-09-2019]

STERNTHAL, B., DHOLAKIA, R. y LEAVITT, C. (1978): The persuasive effect of source credibility: Tests of cognitive response. Journal of Consumer Research, 4(4), pp. 252-260. https://doi.org/10.1086/208704.

STRÖMBÄCK, J. y KIOUSIS, S. (Eds.) (2011): Political public relations: Defining and mapping an emergent field, en STRÖMBÄCK, J. y KIOUSIS, S.: Political Public Relations: Principles and Applications. pp. 1-32. Nueva York y Londres: Routledge.

TANKARD, J. W. (2001): The empirical approach to the study of media framing, en REESE, S. D., GANDY JR., O. H. y GRANT, A. E.: Framing Public Life: Perspectives on Media and our Understanding of the Social World. pp. 95-105. Mahwah, (EE.UU.): Lawrence Erlbaum Associates.

TODOROV, A., MANDISODZA, A. N., GOREN, A. y HALL, C. C. (2005): Inferences of competence from faces predict election outcomes. Science, 308(5728), pp. 1623-1626. https://doi.org/10.1126/science.1110589.

VACCARI, C., CHADWICK, A. y O'Loughlin, B. (2015): Dual screening the political: Media events, social media, and citizen engagement. Journal of Communication, 65(6), pp. 10411061. 
VALENZUELA, S. y MCCOMBS, M. E. (2007): Agenda-setting effects on vote choice: Evidence from the 2006 Mexican election, en Proceedings of the 57th Annual Conference of the International Communication Association. San Francisco, USA, 24-28 de mayo de 2007., International Communication Association.

VAN-ZUYDAM, S. y HENDRICKS, F. (2018): Credibility enacted: Understanding the meaning of credible political leadership in the Dutch parliamentary election campaign of 2010. Journal of Political Marketing, 17(3), pp. 258-281.

WANG, H., CAN, D., KAZEMZADEH, A., BAR, F. y NARAYANAN, S. (2012): A system for real-time twitter sentiment analysis of 2012 US presidential election cycle, en Proceedings of the 5oth Annual Meeting of the Association for Computational Linguistics. Jeju, Corea del Sur, 8-14 de julio de 2012. Association for Computational Linguistics, pp. 115-120. Disponible en: http://delivery.acm.org/10.1145/2400000/2390490/p115wang.pdf?ip $=81.33 \cdot 94 \cdot 118 \& i d=2390490 \& a c c=O P E N \& k e y=4 D 4702 B o C 3 E_{3} 8 B 35 \% 2 E 4 D 4$ 702BoC3E38B35\%2E4D4702BoC3E38B35\%2E6D218144511F3437\&_acm_=15692693 62_8b19c6213d2ac33feo98b946ebdob198.

WEST, R. y TURNER, L. H. (2004): Introducing Communication Theory. Analysis and application. 2da ed., Nueva York: McGraw-Hill.

WIMMER, R. D. y DOMINICK, J. R. (1996): La investigación científica de los medios de comunicación. Una introducción a sus métodos. Barcelona: Bosch.

WINTERSIECK, A. L. (2017): Debating the Truth: The Impact of Fact-Checking During Electoral Debates. American Politics Research, 45(2), pp. 304-331.

ZALLER, J. R. (1992): The nature and origins of mass opinion. Cambridge (EE.UU.): Cambridge University Press. 